\title{
Alterations of Ventilation to Perfusion Ratios Distribution Associated with Successive Clinical Stages of Pulmonary Emphysema*
}

\author{
Claude Lenfant $\dagger$ and William R. Pace, Jr. \\ (From the Institute of Respiratory Physiology, Firland Sanatorium, and the Departments of \\ Medicine and Physiology, University of Washington School of Medicine, \\ Seattle, Wash.)
}

Studies reported by Briscoe and co-workers (1) and Finley (2) have demonstrated the blood gas abnormalities of patients with pulmonary emphysema to be mainly the result of impaired distribution of the ventilation to perfusion $(\dot{\mathrm{V}} \mathrm{A} / \dot{\mathrm{Q}})$ ratios throughout the lung. Finley provided no information about the differences in clinical severity of his subjects, however, and Briscoe and co-workers apparently studied patients representing only one stage of the disease according to the classification of Baldwin, Cournand, and Richards (3). Thus, neither study established the actual nature of changes in $\dot{\mathrm{V}}_{\mathrm{A}} / \dot{\mathrm{Q}}$ distribution that develop as the disease progresses. Unanswered is the question of whether there occurs an increase of range, ${ }^{1}$ of dispersion, or of both. Yet it is important to know what modifications develop as the disease worsens, because knowledge of these progressive changes may lead to a better understanding of the basic physiological impairments occurring with age $(4,5)$. This paper is a report of experiments that were made in an attempt to assess the nature of the differences in $\dot{V}_{\mathrm{A}} / \dot{\mathrm{Q}}$ distribution present in three groups of subjects selected ac-

* Submitted for publication September 10, 1964; accepted June 7, 1965.

This work was supported by the National Institutes of Health, grants H-08465 and H-01892.

$\dagger$ Address requests for reprints to Dr. Claude Lenfant, Institute of Respiratory Physiology, Firland Sanatorium, 1704 N.E. 150th St., Seattle 55, Wash.

"As used in this discussion, the terms "over-all," "range," "dispersion," and "frequency distribution" are defined as follows: "over-all" refers to the whole lung (e.g., $\dot{\mathrm{V}}_{\mathrm{AT}} / \dot{\mathrm{Q}}_{\mathrm{T}}$ is the over-all $\dot{\mathrm{V}}_{\mathrm{A}} / \dot{\mathrm{Q}}$; "range" is the interval between the highest and the lowest figures; "dispersion" is the variation in size occurring among the various items constituting the series, and "frequency distribution" is defined as an arrangement of numerical data according to size. cording to the clinical severity of their pulmonary emphysema.

\section{Methods}

Subjects

Twenty-two hospitalized patients have been studied. Upon physical examination, they all had symptoms and findings consistent with some degree of obstructive bronchopulmonary disease. All had chronic coughs and some shortness of breath. Some had pulmonary fibrosis in addition to emphysematous changes, and most of them had tuberculosis when they were studied, or had had this disease at some time in the past. In this study the subjects were classified into three groups on the basis of the severity of their clinical symptoms and the impairment of spirometrically measured ventilatory function.

Group I comprised six patients who did not complain of shortness of breath at rest, but who became dyspneic with moderate exertion and had maximal expiratory flow (MEF) rates greater than $180 \mathrm{~L}$ per minute. Whereas some of the subjects in this group had numerical values for MEF, or maximal breathing capacities (MBC) that were borderline or even normal, these patients had forced expiratory spirograms that demonstrated slowing of the expiratory flow in some portion of the tracing. Group II was composed of nine patients, each with recurring symptoms while resting, and each suffering from enough dyspnea to prevent any prolonged physical activity. The maximal breathing capacities of these patients varied from 34 to $76 \mathrm{~L}$ per minute, with a mean value of 55 ; mean MEF measurement for this group was $113 \mathrm{~L}$ per minute, and all but one member had MEF values between 70 and 120 Group III comprised seven patients with crippling breathlessness, MBC between 13 and $52 \mathrm{~L}$ per minute, and MEF between 50 and $100 \mathrm{~L}$ per minute. These patients were confined to bed most of the day and capable of only minimal physical activity.

The ages, body surface areas, and available results of routine ventilatory testing for these patients are recorded in Table I. Progressive incapacity is accompanied by a corresponding increase in obstructive and restrictive ventilatory defects.

\section{Procedure}

The day before the experiment, the patient received a preliminary detailed explanation from the investigators 
TABLE I

Statistical and basic respiratory data for all subiects

\begin{tabular}{|c|c|c|c|c|c|c|c|c|}
\hline & $\begin{array}{c}\text { Subject } \\
\text { no. }\end{array}$ & Age & $\begin{array}{l}\text { Body } \\
\text { surface } \\
\text { area }\end{array}$ & $\begin{array}{c}\text { Vital } \\
\text { capacity }\end{array}$ & $\begin{array}{l}\text { Comparison } \\
\text { to predicted* } \\
\text { value }\end{array}$ & 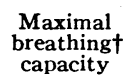 & $\begin{array}{l}\text { Comparison } \\
\text { to predicted* } \\
\text { value }\end{array}$ & $\begin{array}{c}\text { Maximal } \\
\text { expiratory } \\
\text { flow }\end{array}$ \\
\hline \multirow[t]{8}{*}{. } & Group I & years & $m^{2}$ & $L$ & $\%$ & $L / \min$ & $\%$ & $L / \min$ \\
\hline & $\begin{array}{l}1 \\
2 \\
3 \\
4 \\
5 \\
6\end{array}$ & $\begin{array}{l}53 \\
50 \\
44 \\
60 \\
50 \\
46\end{array}$ & $\begin{array}{l}1.75 \\
2.16 \\
1.67 \\
1.45 \\
2.16 \\
1.96\end{array}$ & $\begin{array}{l}3.97 \\
4.00 \\
4.50 \\
1.96 \\
5.86 \\
3.20\end{array}$ & $\begin{array}{r}105 \\
88 \\
115 \\
59 \\
144 \\
72\end{array}$ & 91 & 90 & $\begin{array}{l}240 \\
360 \\
340 \\
180 \\
320 \\
220\end{array}$ \\
\hline & $\begin{array}{c}\text { Mean } \\
\text { of }\end{array}$ & 50 & 1.86 & $\begin{array}{l}3.91 \\
1.30\end{array}$ & $\begin{array}{l}97.2 \\
30.8\end{array}$ & & & $\begin{array}{r}276.7 \\
73.1\end{array}$ \\
\hline & \multicolumn{8}{|c|}{ Group II } \\
\hline & $\begin{array}{r}7 \\
8 \\
9 \\
10 \\
11 \\
12 \\
13 \\
14 \\
15\end{array}$ & $\begin{array}{l}53 \\
65 \\
49 \\
56 \\
53 \\
74 \\
47 \\
72 \\
41\end{array}$ & $\begin{array}{l}1.96 \\
1.74 \\
1.76 \\
1.54 \\
1.96 \\
1.50 \\
1.56 \\
1.67 \\
1.60\end{array}$ & $\begin{array}{l}3.16 \\
1.60 \\
3.39 \\
1.85 \\
3.16 \\
3.38 \\
2.83 \\
1.88 \\
3.33\end{array}$ & $\begin{array}{r}83 \\
48 \\
90 \\
50 \\
83 \\
109 \\
82 \\
55 \\
85\end{array}$ & $\begin{array}{l}61 \\
39 \\
75 \\
41 \\
61 \\
76 \\
50 \\
34 \\
58\end{array}$ & $\begin{array}{r}53 \\
43 \\
69 \\
46 \\
53 \\
106 \\
65 \\
41 \\
56\end{array}$ & $\begin{array}{r}100 \\
100 \\
100 \\
120 \\
100 \\
200 \\
120 \\
70 \\
110\end{array}$ \\
\hline & $\begin{array}{c}\text { Mean } \\
\sigma\end{array}$ & 57 & 1.70 & $\begin{array}{l}2.73 \\
0.70\end{array}$ & $\begin{array}{l}76.1 \\
19.4\end{array}$ & $\begin{array}{l}55 \\
14.3\end{array}$ & $\begin{array}{l}59.1 \\
19.0\end{array}$ & $\begin{array}{r}113.1 \\
33.7\end{array}$ \\
\hline & \multicolumn{8}{|c|}{ Group III } \\
\hline & $\begin{array}{c}16 \\
17 \\
18 \\
19 \\
20 \\
21 \\
22 \\
\text { Mean } \\
\sigma\end{array}$ & $\begin{array}{l}43 \\
60 \\
56 \\
55 \\
57 \\
56 \\
63 \\
56\end{array}$ & $\begin{array}{l}1.71 \\
1.63 \\
1.59 \\
1.80 \\
1.24 \\
1.54 \\
1.85 \\
1.62\end{array}$ & $\begin{array}{l}1.96 \\
1.93 \\
1.82 \\
3.12 \\
1.06 \\
2.40 \\
3.40 \\
2.24 \\
0.74\end{array}$ & $\begin{array}{l}51 \\
52 \\
52 \\
70 \\
41 \\
65 \\
93 \\
60.6 \\
16.0\end{array}$ & $\begin{array}{l}21 \\
27 \\
21 \\
52 \\
13 \\
34 \\
39 \\
29.6 \\
12.2\end{array}$ & $\begin{array}{l}19 \\
30 \\
23 \\
50 \\
25 \\
39 \\
39 \\
32.1 \\
10.2\end{array}$ & $\begin{array}{r}60 \\
90 \\
80 \\
100 \\
50 \\
80 \\
100 \\
80 \\
17.7\end{array}$ \\
\hline
\end{tabular}

* The predicted values of vital capacity and of maximal expiratory flow were established from the standard values, given in reference 6 .

† The maximal breathing capacity was not available for all the subjects of group I.

$\ddagger \sigma=$ standard deviation.

who would carry out the procedure. After an arterial puncture, the subject was seated in a comfortable chair. His nose was occluded with a nose clamp, and a rubber mouthpiece was fitted into his mouth and checked for leaks. The mouthpiece was connected to a two-way plastic valve, having a $30-\mathrm{ml}$ dead space.

The subject first inspired an argon-free gas in which the fractional concentrations of $\mathrm{O}_{2}$ and $\mathrm{N}_{2}$ were comparable to those in room air. After an adaptation period of 10 minutes, the expired gas was collected while a sample of arterial blood was being withdrawn. The inspired gas was then changed to a mixture of $90 \% \mathrm{O}_{2}$ and $10 \% \mathrm{~N}_{2}$ with no argon. The subject breathed this mixture for 11 to 15 minutes before samples of arterial blood and expired gas were again collected simultaneously. The subject then resumed breathing the gas mixture simulating room air; the final blood and gas samples were simultaneously cọllected 10 to 15 minutes later.
Throughout the entire procedure, the concentrations of expired $\mathrm{CO}_{2}$ and $\mathrm{N}_{2}$ at mouth level were continuously monitored with an infrared $\mathrm{CO}_{2}$ analyzer and a nitrogen meter, both of which were calibrated with standard gas mixtures before and after each experiment. The concentration of $\mathrm{O}_{2}$ at any moment was calculated as the difference between $100 \%$ and the sum of the $\mathrm{CO}_{2}$ and $\mathrm{N}_{2}$ concentrations. Expiratory flow and integrated volume were constantly monitored with a Godart pneumotachograph. In some experiments the pressure at mouth level was recorded during inspiration and expiration in order to calculate the resistance of the system. The resistance never exceeded $0.2 \mathrm{~cm} \mathrm{H}_{2} \mathrm{O}$ per $\mathrm{L}$ per second.

Beckman $\mathrm{O}_{2}$ and Severinghaus $\mathrm{CO}_{2}$ electrodes were used to measure $\mathrm{PO}_{2}$ and $\mathrm{PCO}_{2}$ of the collected samples of arterial blood and expired gas. The samples were tested within less than 5 minutes after collection. A delay of 5 . minutes could cause approximately $2 \mathrm{~mm} \mathrm{Hg}$ underestima- 


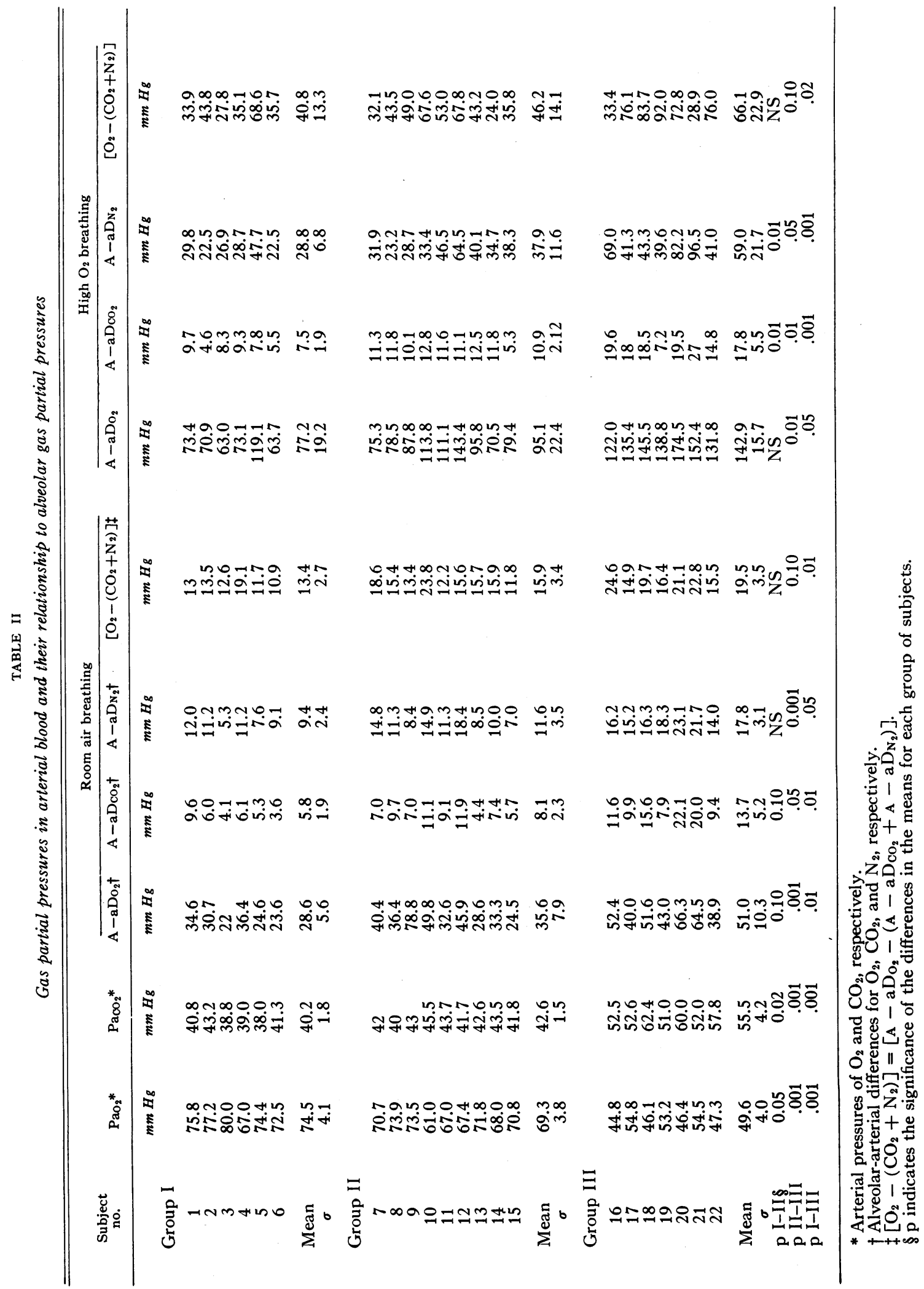


tion of arterial oxygen pressure $\left(\mathrm{Pa}_{\mathrm{O}_{2}}\right)$ during room air breathing, and about $14 \mathrm{~mm} \mathrm{Hg}$ lowering of $\mathrm{O}_{2}$ tension of the high $\mathrm{FI}_{\mathrm{O}_{2}}{ }^{2}$ samples; the overestimation of $\mathrm{PaCO}_{2}$ resulting from this short a wait would be insignificantly small (7). The electrodes were calibrated with tonometered samples of blood immediately before and after each analysis. All measurements were made at $37.5^{\circ} \mathrm{C}$.

A portion of each blood sample was kept anaerobically until the end of the experiment, when it was analyzed for $\mathrm{PN}_{2}$ with a Beckman CG2A gas chromatograph. The nitrogen concentration in a mixed expired sample was calculated as the difference between $100 \%$ and the sum of the $\mathrm{O}_{2}$ and $\mathrm{CO}_{2}$ concentrations.

For the determination of alveolar-arterial differences $(\mathrm{A}-\mathrm{aD})$ in gas tensions, and for plotting the washout and washin, the concentrations of end tidal expired gas were assumed to represent the gas concentrations in the alveoli. The amount of $\mathrm{N}_{2}$ eliminated from the tissues while the subject breathed $90 \% \mathrm{O}_{2}$ was determined according to the data of Robertson, Siri, and Jones (8), corrected for the subject's weight.

\section{Calculations}

Total alveolar ventilation. Alveolar ventilation $\left(\dot{\mathrm{V}}_{\mathrm{A}}\right)$ was determined as the product of the total expired ventilation $(\dot{\mathrm{VE}})$ and the ratio of $\mathrm{CO}_{2}$ concentration in expired gas to that in end tidal gas, according to the equation: $\dot{\mathrm{VA}}=\dot{\mathrm{VE}}\left(\mathrm{FE}_{\mathrm{CO}_{2}} / \mathrm{F}_{\mathrm{ACO}_{2}}\right)$. The results in Table II are expressed in conditions BTPS. ${ }^{3}$

Washout and washin curves. The method originally described by Briscoe and Cournand (9) was used in a slightly modified form. On semilogarithmic paper, time was expressed along the linear abscissa, and the values of alveolar $\mathrm{N}_{2}$ concentration minus alveolar $\mathrm{N}_{2}$ concentration at infinity were expressed along the logarithmic ordinate according to the equation: $\left(F_{A_{t}}-F_{A_{\infty}}\right) /\left(F_{A_{0}}-F_{A_{\infty}}\right)$ $=\mathrm{e}^{-\mathbf{k t}}$, where $\mathrm{F}_{\mathbf{A}_{0}}, \mathbf{F}_{\mathbf{A}_{\mathrm{t}}}$, and $\mathrm{F}_{\mathbf{A}_{\infty}}$ are, respectively, the measured $\mathrm{N}_{2}$ concentrations before the study, at time $t$ during the study, and after infinite time, and $\mathrm{k}$ is equal to the ratio of alveolar ventilation to lung volume $\left(\dot{V}_{A} / V_{L}\right)$.

The washout and washin curves for each subject were analyzed into three exponential components, corresponding to the lung compartments having different ventilatory rates. The component representing the compartment having the poorest ventilation was easily derived in the usual manner. Occasional difficulty was encountered in differentiating the best ventilated and the intermediate compartments, principally with curves for subjects from group I.

The ventilation of each compartment was calculated

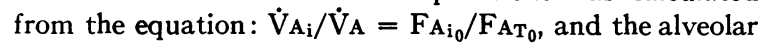
ventilation per unit of lung volume from the equation: $\dot{\mathrm{V}}_{\mathbf{A}_{\mathbf{i}}} / \mathrm{VL}_{\mathbf{i}}=\mathrm{M} / 2.3$. In these equations, $\dot{\mathrm{V}}_{\mathbf{A}_{\mathbf{i}}}$ and $\dot{\mathrm{V}}_{\mathbf{A}}$ are, respectively, the alveolar ventilation per minute of any compartment and of the whole lung; $\mathrm{VL}_{\mathbf{i}}$ is the volume in milliliters of that compartment, $\mathbf{F}_{\mathbf{A}_{\mathrm{i}_{0}}}$ is the nitrogen concentration in the same compartment at time zero; $F_{A_{T}}$ is

\footnotetext{
${ }^{2}$ Fractional concentration of $\mathrm{O}_{2}$ in inspired gas.

${ }^{3}$ Body temperature, pressure, saturated with water.
}

the mixed alveolar nitrogen concentration; $M$ is the number of units of time in which a single exponential function falls to $\frac{1}{10}$ of any previous value, and 2.3 is $\log _{e} 10$.

The volume of each compartment was determined from these equations, and the total lung volume $\left(V_{L}\right)$ was computed as the sum of the volumes of all compartments $\left(V_{L_{i}}+\cdots V_{L_{n}}\right)$. For simplicity the three compartments will be designated hereafter by the numbers 1,2 , and 3 , referring, respectively, to the most ventilated, the intermediately ventilated, and the least ventilated compartments, in relation to their volumes.

Determination of $\dot{Q}$. Assessment of the distribution of blood flow within the three compartments required several assumptions, each of which will be discussed in turn.

a) $\dot{\mathrm{V}}_{\mathrm{A}} / \dot{\mathrm{Q}}$ is assumed to be the same throughout (i.e., not distributed within) each of the compartments identified from the $\mathrm{N}_{2}$ washout data. This assumption is necessary if the number of compartments is to be kept within manageable limits.

b) $\dot{\mathrm{V}}_{\mathrm{A}} / \dot{\mathrm{Q}}$ is assumed to be lower in compartments with less ventilation per unit volume. In any case where this is not true, our interpretation is not valid. In the patients studied in these experiments, however, the washout data indicate that those parts of the lung with lowest $\dot{V}_{A} / \mathrm{VL}$ ratios constitute a significantly large fraction of the total lung volume, accounting for $71 \%$ of the functional residual capacity (FRC) in group III and $46 \%$ in group I. Our assumption, then, is that such a large part of the lung must be perfused by a substantial portion of the cardiac output. Hence, since its ventilation is so much less than that of other parts of the lung, this larger compartment must have the lowest $\dot{\mathrm{V}}_{\mathrm{A}} / \dot{\mathrm{Q}}$. Although this assumption will be reviewed in detail in the Discussion, it must be kept in mind that these compartments, so defined, have no spatial significance whatsoever. The technique used in our experiments considers units with the same functional properties from all over the lung as grouped together in each compartment. The findings, therefore, of regional function studies (10-11), which, by contrast, group together in variable proportions units with different characteristics, do not refute our assumption.

c) A- $\mathrm{aD}_{\mathrm{N}_{2}}$ is considered as being determined exclusively by the group of low $\dot{V}_{A} / \dot{Q}$ units. This assumption is not entirely accurate, since the better ventilated spaces also make a small contribution; where the assumption is invalid, the resulting error would minimize the ventilation to perfusion ratios of the slow spaces.

d) $\mathrm{A}-\mathrm{aDCO}_{2}$ is assumed to be determined exclusively by the group of units with the highest $\dot{\mathrm{V}}_{\mathrm{A}} / \dot{\mathrm{Q}}$. If this postulate is not valid, the estimates of the $\dot{V}_{A} / \dot{Q}$ in the better ventilated spaces are maximal values.

e) Total blood flow is assumed to be $5 \mathrm{~L}$ per minute, and the same in all subjects. Deviations from this estimate by $30 \%$ in either direction were found to cause no appreciable difference in results from this system of interpretation.

On the basis of these assumptions, the value of $\dot{Q}_{3}$ was obtained by determining the blood flow necessary to produce the measured $\mathrm{A}-\mathrm{a} \mathrm{D}_{\mathrm{N}_{2}}$, when the alveolar ventilation was equal to $\dot{\mathrm{V}}_{\mathrm{A}_{3}}$, as derived from the $\mathrm{N}_{2}$ washout curve. 
TABLE III

Ventilation*

\begin{tabular}{|c|c|c|c|c|c|c|c|c|c|c|c|c|}
\hline \multirow{2}{*}{$\begin{array}{c}\text { Subject } \\
\text { no. } \\
\text { Compartment }\end{array}$} & \multirow[b]{2}{*}{$\dot{\mathrm{V}}_{\mathrm{AT}}$} & \multicolumn{3}{|c|}{$\dot{\mathrm{V}}_{\mathbf{A}} / \dot{\mathrm{V}}_{\mathbf{A T}}$} & \multirow[b]{2}{*}{ VLT } & \multicolumn{3}{|c|}{$V_{L} / V_{L T}$} & \multirow[b]{2}{*}{$\dot{\mathrm{V}}_{\mathrm{AT}} / \mathrm{V}_{\mathbf{L T}}$} & \multicolumn{3}{|c|}{$\dot{\mathrm{V}}_{\mathbf{A}} / \mathrm{V}_{\mathbf{L}}$} \\
\hline & & 1 & 2 & 3 & & 1 & 2 & 3 & & 1 & 2 & 3 \\
\hline & $m l / m i n$ & & $\%$ & & $m l$ & & $\%$ & & $\underset{\mathrm{min}}{\mathrm{ml} / \mathrm{ml} /}$ & & $m l / m$ & \\
\hline \multicolumn{13}{|l|}{ Group I } \\
\hline 1 & 4,572 & 36.7 & 54.3 & 9.0 & 2,959 & 11.2 & 49.3 & 39.5 & 1.88 & 5.11 & 1.70 & 0.35 \\
\hline 2 & 6,380 & 30.6 & 52.6 & 16.8 & 3,804 & 7.5 & 38.3 & 54.2 & 1.68 & 6.85 & 2.30 & 0.52 \\
\hline 3 & 4,473 & 38.1 & 39.7 & 22.2 & 3,599 & 10.4 & 39.6 & 50.0 & 1.24 & 3.43 & 1.24 & 0.52 \\
\hline 4 & 4,741 & 49.6 & 31.4 & 19.0 & 3,548 & 10.1 & 26.4 & 63.5 & 1.34 & 6.52 & 1.59 & 0.40 \\
\hline 5 & 7,275 & 43.2 & 46.4 & 10.4 & 4,484 & 16.7 & 45.9 & 37.4 & 1.62 & 4.18 & 1.64 & 0.45 \\
\hline 6 & 4,430 & 34.4 & 58.6 & 7.0 & 3,144 & 9.5 & 35.8 & 34.7 & 1.41 & 5.11 & 1.48 & 0.28 \\
\hline Mean & 5,311 & 38.7 & 47.2 & 14.1 & 3,589 & 10.9 & 42.6 & 46.5 & 1.52 & 5.20 & 1.66 & 0.42 \\
\hline$\sigma$ & 1,107 & 5.9 & 9.3 & 5.5 & 491 & 2.8 & 9.3 & 10.2 & 0.22 & 1.20 & 0.32 & 0.09 \\
\hline \multicolumn{13}{|l|}{ Group II } \\
\hline 7 & 5,636 & 57.0 & 26.5 & 16.5 & 3,680 & 13.3 & 22.9 & 63.8 & 1.53 & 6.57 & 1.77 & 0.40 \\
\hline 8 & 5,075 & 49.2 & 42.2 & 8.6 & 3,094 & 17.5 & 39.8 & 42.7 & 1.64 & 4.60 & 1.74 & 0.33 \\
\hline 9 & 5,673 & 49.2 & 45.8 & 5.0 & 3,556 & 13.6 & 63.1 & 23.3 & 1.58 & 5.75 & 1.75 & 0.34 \\
\hline 10 & 6,023 & 38.9 & 39.6 & 21.5 & 6,471 & 7.9 & 25.7 & 66.4 & 0.93 & 4.60 & 1.44 & 0.30 \\
\hline 11 & 5,207 & 53.0 & 25.3 & 21.7 & 4,976 & 9.2 & 24.0 & 66.8 & 1.05 & 6.05 & 1.10 & 0.34 \\
\hline 12 & 4,869 & 46.9 & 29.2 & 23.9 & 4,449 & 12.8 & 20.2 & 67.0 & 1.10 & 4.00 & 1.59 & 0.39 \\
\hline 13 & 4,370 & 41.4 & 38.6 & 20.0 & 4,375 & 7.4 & 34.4 & 58.2 & 1.00 & 5.61 & 1.12 & 0.34 \\
\hline 14 & 5,943 & 39.7 & 40.4 & 19.9 & 5,895 & 8.2 & 33.4 & 58.4 & 1.00 & 4.89 & 1.22 & 0.34 \\
\hline 15 & 4,635 & 45.0 & 33.6 & 21.4 & 4,342 & 9.4 & 33.5 & 57.1 & 1.07 & 3.98 & 1.07 & 0.40 \\
\hline Mean & 5,266 & 46.7 & 35.7 & 17.6 & 4,538 & 11.0 & 33.0 & 56.0 & 1.21 & 5.11 & 1.42 & 0.35 \\
\hline$\sigma$ & 548 & 5.8 & 7.1 & 6.1 & 1,266 & 3.2 & 12.3 & 13.6 & 0.27 & 0.86 & 0.28 & 0.03 \\
\hline \multicolumn{13}{|l|}{ Group III } \\
\hline 16 & 5,277 & 42.4 & 38.4 & 19.2 & 5,342 & 7.6 & 25.6 & 66.8 & 0.98 & 5.47 & 1.48 & 0.28 \\
\hline 17 & 3,823 & 52.0 & 27.0 & 21.0 & 4,817 & 8.2 & 26.5 & 65.5 & 0.79 & 5.11 & 0.81 & 0.25 \\
\hline 18 & 4,416 & 50.5 & 26.5 & 23.0 & 6,585 & 4.0 & 16.9 & 79.1 & 0.67 & 6.00 & 1.05 & 0.20 \\
\hline 19 & 4,720 & 54.7 & 23.9 & 21.4 & 5,754 & 9.2 & 22.6 & 68.2 & 0.82 & 4.84 & .87 & 0.25 \\
\hline 20 & 3,262 & 53.1 & 29.7 & 17.2 & 4,805 & 9.5 & 12.7 & 77.8 & 0.68 & 3.83 & 1.58 & 0.15 \\
\hline 21 & 4,900 & 51.7 & 33.5 & 14.8 & 5,910 & 13.7 & 16.0 & 70.8 & 0.83 & 3.07 & 1.74 & 0.18 \\
\hline 22 & 4,318 & 42.6 & 33.8 & 23.6 & 6,522 & 6.4 & 22.3 & 71.3 & 0.66 & 4.42 & 1.00 & 0.22 \\
\hline Mean & 4,388 & 49.6 & 30.4 & 20.0 & 5,676 & 8.3 & 20.4 & 71.3 & 0.77 & 4.68 & 1.21 & 0.22 \\
\hline$\sigma$ & 627 & 4.6 & 4.7 & 2.9 & 677 & 2.8 & 4.84 & 4.89 & 0.11 & 0.92 & 0.34 & 0.13 \\
\hline p I-II & NS & 0.02 & 0.05 & NS & 0.10 & NS & 0.10 & NS & 0.05 & NS & NS & 0.10 \\
\hline p II-III & 0.01 & NS & 0.10 & NS & 0.05 & 0.02 & 0.02 & 0.01 & 0.001 & NS & NS & 0.02 \\
\hline p I-III & 0.10 & 0.01 & 0.001 & 0.05 & 0.001 & NS & 0.001 & 0.001 & 0.001 & NS & 0.05 & 0.01 \\
\hline
\end{tabular}

* Ventilation $\left(\dot{\mathrm{V}}_{\mathrm{A}}\right)$, lung volume $\left(\mathrm{VL}_{\mathrm{L}}\right)$, and ventilation to lung volume ratio $\left(\dot{\mathrm{V}}_{\mathrm{A}} / \mathrm{VL}\right)$ for the total lung $(\mathrm{r})$, and for each compartment.

It is obvious from Equation 1,

$$
\frac{\dot{Q}_{3}}{\dot{Q}_{T}}=\frac{A-a D_{N_{2}}}{P_{A_{\mathbf{N}_{2}}}-P_{A_{N_{2}}}}
$$

that $\dot{Q}_{3} / \dot{Q}$ will be smallest if there is no active ventilation, since then $\mathrm{PA}_{\mathbf{A}_{\mathrm{N}_{2}}}$ would be as high as it can possibly become. On the other hand, $\mathrm{PA}_{\mathbf{A}_{\mathbf{N}_{2}}}$ decreases as ventilation increases, so that $\dot{Q}_{3} / \dot{Q}_{\mathrm{T}}$ increases as a function of the increasing ventilation.

It is not possible to calculate $\mathrm{P}_{\mathbf{A}_{\mathbf{B}_{\mathbf{N}}}}$ directly from the actual ventilation of the low $\dot{V}_{A} / \dot{Q}$ units, because measurement of $\dot{\mathrm{Vo}}_{2}$ is required for the alveolar ventilation equation. Therefore, the $\dot{Q}_{3}$ corresponding to $\dot{V}_{\mathbf{A}_{3}}$ was calculated by a somewhat more laborious process. First, the value of $\dot{Q}_{3} / \dot{Q}_{\mathrm{T}}$ at an arbitrarily selected value for $\mathrm{P}_{\mathbf{A}_{\mathbf{3}_{\mathbf{2}}}}$ was determined by substituting the latter and the known values of $\mathrm{A}-\mathrm{aD}_{\mathrm{N}_{2}}$ and $\mathrm{PA}_{\mathrm{N}_{2}}$ in Equation 1 . Then, the difference in $\mathrm{O}_{2}$ content between the mixed venous blood and the capillary blood of $\mathrm{VL}_{3}$ was estimated from the
$\mathrm{O}_{2}-\mathrm{CO}_{2}$ diagram, in order to determine the $\mathrm{O}_{2}$ consumption of this particular group of units. With this information, a value for $\dot{\mathrm{V}}_{\mathrm{A}_{3}}$ that would correspond to the arbitrary value of $\mathrm{P}_{\mathrm{A}_{\mathrm{N}_{2}}}$ could be calculated from the alveolar air equation. Repeating these steps with a series of decreasing values for $\mathrm{P}_{\mathbf{A}_{\mathbf{N}_{2}}}$ provided a plot of $\dot{\mathrm{Q}}_{3}$ versus $\dot{\mathrm{V}}_{\mathrm{A}_{3}}$, from which we could select a value of $\dot{Q}_{3}$ corresponding to the actual value of $\dot{\mathrm{V}}_{\mathbf{A}_{\mathbf{3}}}$.

By a somewhat simpler process, $\dot{Q}_{1}$ was calculated from A-aDco 2 . The partial pressure of $\mathrm{CO}_{2}$ in $\mathrm{VL}_{1}\left(\mathrm{PA}_{\mathbf{1} \mathrm{CO}_{2}}\right)$ was calculated according to Equation 2,

$$
\frac{\dot{\mathrm{V}}_{\mathrm{A}_{1}}}{\dot{\mathrm{V}}_{\mathrm{AT}_{\mathrm{T}}}}=\frac{\mathrm{A}-\mathrm{aD}_{\mathrm{CO}_{2}}}{\mathrm{PaCO}_{2}-\mathrm{PA}_{\mathrm{A}_{\mathrm{CO}_{2}}}} \text {. }
$$

The $\mathrm{CO}_{2}$ content of the capillary blood from compartment 1 was determined from the $\mathrm{O}_{2}-\mathrm{CO}_{2}$ diagram, on the assumption that the blood from this compartment would be fully saturated with $\mathrm{O}_{2}$. Then $\dot{Q}_{1}$ was calculated from the equation, $\dot{Q}_{1}=\dot{V}_{\mathrm{A}_{1}} \times \mathrm{PA}_{\mathrm{A}_{\mathbf{C O}_{2}}} / 0.863\left(\mathrm{Cv}_{\mathrm{CO}_{2}}-\mathrm{Ca}_{1_{\mathrm{CO}_{2}}}\right)$. 
$\left(\mathrm{CvCO}_{2}=\right.$ venous concentration of $\mathrm{CO}_{2} ; \mathrm{Ca}_{\mathbf{C O}_{2}}=$ arterial concentration of $\mathrm{CO}_{2}$ in compartment 1.)

Blood flow to compartment 2 was assumed to be the difference between the total blood flow and the sum of perfusion of the other two compartments: $\dot{Q}_{2}=\dot{Q}_{T}$ - $\left(\dot{Q}_{1}+\dot{Q}_{3}\right)$.

\section{Results}

Blood gases (Table II). Significant differences in mean values for $\mathrm{Pa}_{2}$ and $\mathrm{PaCO}_{2}$ for the three groups occurred when the subjects were breathing the mixture simulating room air. Although not as significant, similar differences were observed between the mean values for $\mathrm{A}-\mathrm{aDo}_{2}$, $\mathrm{A}-\mathrm{aDCO}$, and $\mathrm{A}-\mathrm{aDN}$. After the change to $90 \%$ $\mathrm{O}_{2}$, the $\mathrm{A}-\mathrm{aD}$ increased for all gases, as would be expected. The magnitude of this increase seemed to be closely related to the size of $\mathrm{A}-\mathrm{aD}$ in the first phase of the experiment. Therefore, significant differences in the mean values for $\mathrm{A}-\mathrm{aDO}_{2}, \mathrm{~A}-\mathrm{aDCO}_{2}$, and $\mathrm{A}-\mathrm{aDN}_{2}$ persisted.

Alveolar ventilation. The values for the total alveolar ventilation listed in the first column of Table III are means for the alveolar ventilation derived for the sampling period before the beginning and at the end of the nitrogen washout. In all subjects, the actual ventilation varied throughout the washout. Consequently, in view of the effect of ventilation on the $\mathrm{N}_{2}$ clearance curve and the slope of the three components derived from it, the mean value for ventilation was felt to be that most suitable for deriving other data.

The mean values of $\dot{V}_{A_{T}}$ for groups I and II were identical, whereas this value was significantly lower in group III, which consisted of hypercarbic patients. Ventilation was unevenly distributed to the three compartments in all subjects. In all three groups, compartment 3 received the lowest proportion of $\dot{\mathrm{V}}_{\mathrm{A}}$, although this fraction was highest for group III and lowest for group I. Compartments 1 and 2 together always received the greater share of ventilation. In group I subjects, however, the ventilation of compartment 2 was greater than that of compartment 1. By contrast, patients in groups II and III had more ventilation of compartment 1 than of compartment 2.

Lung volume. Table III shows a noteworthy increase in total lung volumes of patients, progressing from group I through group III.
Change in these values is apparent between each group and the next, in contrast to alveolar ventilation, for which the mean values of groups I and II were identical.

The poorly ventilated compartment was the largest of the three in all subjects, and its size increased progressively from group I through group III. Compartment 2 was the next largest in size in all groups, but its size progressively decreased from groups I through III, corresponding to the increase in volume of compartment 3. Compartment 1 was the smallest in all three groups, and its proportional relationship to the total lung volume was the same in all groups. Its absolute size, however, became progressively greater from group I through group III, in parallel with the increase in total lung volume. These relationships explain the paradoxical distribution of $\dot{V}_{A}$ to the different compartments in the subjects of the three different categories, and also demonstrate the necessity for considering $\dot{V}_{A}$ in relation to $V_{L}$.

Turnover rate. The alveolar turnover rate for the whole lung was lower by a significant amount for each successive group from I through III. In group II this decrease was a function of the increase in lung volume. Between groups II and III, changes in $\dot{V}_{A}$ as well as in $V_{L}$ were in the direction of leading to a lower $\dot{\mathrm{V}}_{\mathrm{A}} / \mathrm{VL}$.

In all groups, the alveolar units in compartment 2 had a nearly normal turnover rate. Furthermore, in groups I and II, the turnover rate in compartment $2\left(\dot{\mathrm{V}}_{\mathrm{A}_{2}} / \mathrm{VL}_{2}\right)$ was similar to that of the whole lung $\left(\dot{V}_{A_{T}} / V_{L_{T}}\right)$. The discrepancy between $\dot{\mathrm{V}}_{\mathrm{A}_{2}} / \mathrm{VL}_{2}$ and $\dot{\mathrm{V}}_{\mathrm{A}_{\mathrm{T}}} / \mathrm{VL}_{\mathrm{T}}$ in group III resulted from an excessively large number of poorly ventilated units in these patients. The significance of this factor will be discussed later.

The turnover rate of compartment 3 , which was the lowest in all three groups, decreased progressively, although moderately, from group I through group III. The amount of this decrease from one group to the next was lessened, however, by the progressive augmentation of the compartmental ventilation $\left(\dot{\mathrm{V}}_{\mathrm{A}_{3}}\right)$, which occurred even though the total ventilation $\left(\dot{\mathrm{V}}_{\mathrm{A}}\right)$ diminished progressively. The turnover rates of compartment 1 were not significantly different in the three groups. 
TABLE IV

Perfusion*

\begin{tabular}{|c|c|c|c|c|c|c|c|c|c|c|c|}
\hline \multirow{2}{*}{$\begin{array}{c}\text { Subject } \\
\text { no. } \\
\text { Compartment }\end{array}$} & \multicolumn{3}{|c|}{ Q/Q்T } & \multirow[b]{2}{*}{$\dot{\mathrm{Q}}_{\mathrm{T}} / \mathrm{V}_{\mathrm{LT}}$} & \multicolumn{3}{|c|}{$\dot{Q} / V_{L}$} & \multirow[b]{2}{*}{$\dot{\mathrm{V}}_{\mathrm{AT}} / \dot{\mathrm{Q}}_{\mathrm{T}}$} & \multicolumn{3}{|c|}{$\dot{\mathrm{V}}_{\mathbf{A}} / \dot{\mathbf{Q}}$} \\
\hline & 1 & 2 & 3 & & 1 & 2 & 3 & & 1 & 2 & 3 \\
\hline Group I & \multicolumn{3}{|c|}{$\%$} & $m l / m l / m i n$ & \multicolumn{3}{|c|}{$\mathrm{ml} / \mathrm{ml} / \mathrm{min}$} & $m l / m l / m i n$ & \multicolumn{3}{|c|}{$\mathrm{ml} / \mathrm{ml} / \mathrm{min}$} \\
\hline 1 & 2.8 & 64.8 & 32.4 & 1.69 & 0.43 & 2.22 & 1.38 & 0.91 & 11.94 & 0.76 & 0.25 \\
\hline 2 & 6.4 & 54.4 & 39.2 & 1.31 & 1.12 & 1.87 & 0.95 & 1.28 & 6.09 & 1.23 & 0.55 \\
\hline 3 & 11.5 & 53.2 & 35.3 & 1.39 & 1.56 & 1.86 & 0.98 & 0.89 & 2.95 & 0.67 & 0.56 \\
\hline 4 & 13.1 & 46.5 & 40.4 & 1.41 & 1.82 & 2.49 & 0.90 & 0.95 & 3.58 & 0.64 & 0.44 \\
\hline 5 & 14.6 & 62.2 & 23.2 & 1.11 & 0.97 & 1.51 & 0.69 & 1.45 & 4.29 & 1.08 & 0.65 \\
\hline 6 & 11.4 & 65.0 & 23.8 & 1.59 & 1.92 & 1.85 & 1.08 & 0.89 & 2.66 & 0.80 & 0.25 \\
\hline Mean & 10. & 57.7 & 32.3 & 1.42 & 1.30 & 1.97 & 1.00 & 1.06 & 5.25 & 0.86 & 0.45 \\
\hline$\sigma$ & 4.1 & 6.8 & 6.8 & 0.19 & 0.52 & 0.31 & 0.21 & 0.22 & 3.19 & 0.22 & 0.15 \\
\hline \multicolumn{12}{|l|}{ Group II } \\
\hline 7 & 17.7 & 37.3 & 45.0 & 1.36 & 1.82 & 2.20 & 0.96 & 1.13 & 3.62 & 0.80 & 0.41 \\
\hline 8 & 13.4 & 56.6 & 30.0 & 1.62 & 1.24 & 2.30 & 1.13 & 1.01 & 3.73 & 0.76 & 0.29 \\
\hline 9 & 14.8 & 64.8 & 20.4 & 1.41 & 1.53 & 1.44 & 1.23 & 1.13 & 3.75 & 0.80 & 0.27 \\
\hline 10 & 5.0 & 41.0 & 54.0 & 0.77 & 0.49 & 1.24 & 0.64 & 1.20 & 9.40 & 1.16 & 0.48 \\
\hline 11 & 12.4 & 42.6 & 45.0 & 1.00 & 1.36 & 1.78 & 0.68 & 1.04 & 4.45 & 0.62 & 0.50 \\
\hline 12 & 4.3 & 34.1 & 61.6 & 1.12 & 0.37 & 1.90 & 1.03 & 0.97 & 10.65 & 0.84 & 0.39 \\
\hline 13 & 13.6 & 49.4 & 37.0 & 1.14 & 2.12 & 1.64 & 0.73 & 0.87 & 2.65 & 0.68 & 0.47 \\
\hline 14 & 8.5 & 52.3 & 39.2 & 0.85 & 0.88 & 1.33 & 0.57 & 1.19 & 5.54 & 0.92 & 0.60 \\
\hline 15 & 12.7 & 51.3 & 36.0 & 1.15 & 1.55 & 1.76 & 0.72 & 0.93 & 3.29 & 0.61 & 0.55 \\
\hline Mean & 11.4 & 47.7 & 40.9 & 1.16 & 1.26 & 1.73 & 0.85 & 1.05 & 5.23 & 0.80 & 0.44 \\
\hline$\sigma$ & 4.2 & 9.3 & 11.6 & 0.25 & 0.55 & 0.34 & 0.22 & 0.11 & 2.69 & 0.16 & 0.10 \\
\hline \multicolumn{12}{|l|}{ Group II I } \\
\hline 16 & 6.3 & 43.3 & 50.4 & 0.94 & 0.77 & 1.58 & 0.71 & 1.05 & 7.07 & 0.94 & 0.40 \\
\hline 17 & 9.8 & 43.0 & 47.2 & 1.04 & 1.26 & 1.67 & 0.75 & 0.76 & 4.04 & 0.48 & 0.34 \\
\hline 18 & 8.2 & 30.6 & 61.2 & 0.76 & 1.11 & 1.37 & 0.60 & 0.88 & 5.41 & 0.76 & 0.33 \\
\hline 19 & 18.3 & 25.3 & 56.4 & 0.87 & 1.71 & 0.97 & 0.72 & 0.94 & 2.82 & 0.89 & 0.35 \\
\hline 20 & 2.8 & 28.0 & 69.2 & 1.04 & 0.31 & 2.28 & 0.92 & 0.65 & 12.46 & 0.69 & 0.16 \\
\hline 21 & 2.8 & 34.0 & 63.2 & 0.85 & 0.17 & 1.80 & 0.76 & 0.98 & 18.25 & 0.96 & 0.23 \\
\hline 22 & 9.3 & 37.1 & 53.6 & 0.77 & 1.12 & 1.27 & 0.57 & 0.86 & 3.95 & 0.78 & 0.38 \\
\hline Mean & 8.2 & 34.5 & 57.3 & 0.89 & 0.92 & 1.56 & 0.72 & 0.88 & 7.71 & 0.78 & 0.31 \\
\hline$\sigma$ & 4.9 & 6.5 & 7.2 & 0.11 & 0.50 & 0.39 & 0.11 & 0.12 & 5.22 & 0.15 & 0.08 \\
\hline p I-II & NS & 0.05 & 0.10 & 0.05 & NS & NS & NS & NS & NS & NS & NS \\
\hline p II-III & NS & 0.01 & 0.01 & 0.02 & NS & NS & NS & 0.01 & NS & NS & 0.01 \\
\hline p I-III & NS & 0.001 & 0.001 & 0.001 & NS & 0.05 & 0.01 & 0.10 & NS & NS & 0.05 \\
\hline
\end{tabular}
ment.

* Perfusion $(\dot{Q})$, perfusion to lung volume ratio $(\dot{Q} / \mathrm{VL})$, and ventilation to perfusion ratio $(\mathrm{VA} / \mathrm{Q})$ for the total lung $(\mathrm{T})$, and for each compart-

Blood flow. Since the total blood flow was assumed to be the same in all subjects, only the distribution of $\dot{Q}$ to the different compartments is shown in Table IV. Blood flow to compartment 1 did not differ significantly from one group to another. The mean values for compartment 2 , however, progressively decreased while those for compartment 3 correspondingly increased. This increase in $\dot{Q}$ of compartment 3 is similar to the increase in $\dot{V}_{A}$ to that compartment. As in the case of $\dot{V}_{A}$, however, these variations in $\dot{Q}$ must be considered in relation to the volumes of the different compartments.

Ratio of perfusion to lung volume. The fourth column in Table IV shows $\dot{Q}_{\mathrm{T}} / \mathrm{V}_{\mathrm{L}_{\mathrm{T}}}$ decreasing progressively from group I through group III.
This is the direction in which this ratio would be expected to change, corresponding to the progressive increase in $\mathrm{VL}_{\mathrm{T}}$. The $\dot{Q} / \mathrm{V}_{\mathrm{L}}$ in compartments 2 and 3 tended to decrease from group I to group III. The two components of the ratio, however, changed in a dissimilar fashion in the different compartments. In compartment 3 , both $\dot{Q}$ and $V_{L}$ increased progressively from group I through group III, but the increase of $V_{L}$ was greater than that of $\dot{Q}$. In compartment 2, $\dot{Q}$ decreased progressively, as did $V_{L_{2}}$, but the latter decrease was less rapid. There was practically no difference in $\dot{Q}_{1} / V_{L_{1}}$ in the successive groups, in spite of the increase in $V_{L_{1}}$.

Ventilation to perfusion ratio. The average over-all $\dot{\mathrm{V}}_{\mathrm{A}} / \dot{\mathrm{Q}}$ decreased between groups I and 
III. As indicated in Table IV, the $\dot{\mathrm{V}} \mathrm{A} / \dot{\mathrm{Q}}$ differed in the three compartments. In all three groups, $\dot{\mathrm{V}}_{\mathrm{A}_{\mathrm{T}}} / \dot{\mathrm{Q}}_{\mathrm{T}}$ was higher than either $\dot{\mathrm{V}}_{\mathrm{A}_{2}} / \dot{\mathrm{Q}}_{2}$ or $\dot{\mathrm{V}}_{\mathrm{A}_{3}} / \dot{\mathrm{Q}}_{3}$. Between groups, there were only insignificant changes in $\dot{\mathrm{V}}_{\mathrm{A}_{1}} / \dot{\mathrm{Q}}_{1}$ and $\dot{\mathrm{V}}_{\mathrm{A}_{2}} / \dot{\mathrm{Q}}_{2}$.

\section{Discussion}

Comparison of Tables I and II shows a good correlation between the degree of ventilatory impairment and the disturbances of $\mathrm{PO}_{2}$ and $\mathrm{PCO}_{2}$ in the arterial blood. This agrees with the generally accepted concept that disordered blood gas tensions are, in this type of patient, a reflection of the impairment of the ventilation to perfusion ratios distribution throughout the lung. To estimate whether the changes in the frequency distribution of $\dot{V}_{A} / \dot{Q}$ resulted from an increase of range, or of dispersion, or of both, it was necessary to divide the lung into a manageable number of uniform compartments and then to derive the compartmental ventilation and the compartmental perfusion.

Most of these data depend largely on the rate of nitrogen washout, which was estimated from the end tidal values of nitrogen. Particularly in diseased subjects, these values for $\mathrm{N}_{2}$ may not represent the mixed expired alveolar gas. Thus, as pointed out by Briscoe and associates $(1,9)$, although the slope of the straight line into which the semilogarithmic plot is analyzed is not affected by which gas concentration is plotted (mixed expired, end tidal, or forced expiratory), the intercept of those straight lines with the ordinate, and their derivatives, are. Consequently, the values of $\dot{V}_{A} / V_{L}$ given for each compartment in Table II, which depend only on the slope of the line, are reliable. On the other hand, the use of end tidal values leads to overestimation of $\dot{\mathrm{V}}_{\mathrm{A}_{3}} / \dot{\mathrm{V}}_{\mathrm{A}_{\mathrm{T}}}$, and to underestimation of $\dot{\mathrm{V}}_{\mathrm{A}_{1}} / \dot{\mathrm{V}}_{\mathrm{A}_{\mathrm{T}}}$ and $\dot{\mathrm{V}}_{\mathrm{A}_{2}} / \dot{\mathrm{V}}_{\mathrm{A}_{\mathrm{T}}}$. For this reason, the derived values $\dot{V}_{A_{1}}, \dot{V}_{A_{2}}, \dot{V}_{A_{3}}, V_{L_{1}} / V_{L_{T}}, V_{L_{2}} / V_{L_{T}}$, $V_{L_{3}} / V_{L_{T}}$, and $V_{L_{T}}$ are also in error. Yet no effort was made to correct these determinations, whose values, as they stand, lead to minimizing the dispersion of $\dot{\mathrm{V}}_{\mathrm{A}} / \dot{\mathrm{Q}}$ distribution.

Although $\dot{V}_{A} / V_{L}$ should not be influenced by the nature of the gas concentration used in the semilogarithmic plot, other factors might have affected our findings. Torres, Huang, and Lyons have reported an almost instantaneous decrease of lung compliance, accompanied by increased venous admixture when pure $\mathrm{O}_{2}$ is inspired (12). These findings and Briscoe and Cournand's observation (13) of increased perfusion to the poorly ventilated compartment during $\mathrm{O}_{2}$ breathing suggest that some alveoli collapse throughout the period of oxygen breathing.

If $\mathrm{N}_{2}$ washin follows the $\mathrm{N}_{2}$ washout, a change in the slope for compartment 3 should reveal any increase that occurred in the number of closed alveoli when the subject began breathing $90 \%$ $\mathrm{O}_{2}$. Quadrant $\mathrm{D}$ of Figure 1 compares the values of $\dot{V}_{A} / V_{L}$ in each compartment, measured from the $\mathrm{N}_{2}$ washout and washin plot. Although there is an important scattering, no significant difference could be estimated between the two methods. These findings are consistent with results obtained by Briscoe and associates (1), plotted in quadrant $C$. The regression lines between the two sets of data are not different, just as there is no variance in quadrants $A$ and $B$ showing the same kinds of data obtained from patients and normal subjects breathing an $\mathrm{O}_{2}$ concentration no different from that of room air (9). This evidence, in addition to other data (14), strongly refutes the concept that a high $\mathrm{O}_{2}$ concentration in the inspired gas causes an immediate change in the number of closed or collapsed alveoli.

The procedure used to calculate blood flow was based on the several postulates stated previously and also on the use of the end tidal values of the expired gases as the alveolar gases. The case against such a method is strong in patients with disease likely to cause or increase sequential emptying of the lung. As shown by Marshall, Bates, and Christie (15), during the course of an expiration there is an important increase of $\mathrm{CO}_{2}$ and a decrease of $\mathrm{O}_{2}$ in the expired gases. In our subjects, who were quietly breathing, in opposition to forced or prolonged expiration, monitoring of the expired $\mathrm{CO}_{2}$ and $\mathrm{N}_{2}$ also revealed a consistently ascending slope for both. The rates of change were more pronounced in patients of group III, compared to those of patients in groups I and II. However, the final value in $\mathrm{CO}_{2}$ and $\mathrm{O}_{2}$, as calculated from the difference between the total pressure and the sum of $\mathrm{PCO}_{2}$ and $\mathrm{PN}_{2}$, remained within reasonable limits. The means for the subjects of groups 


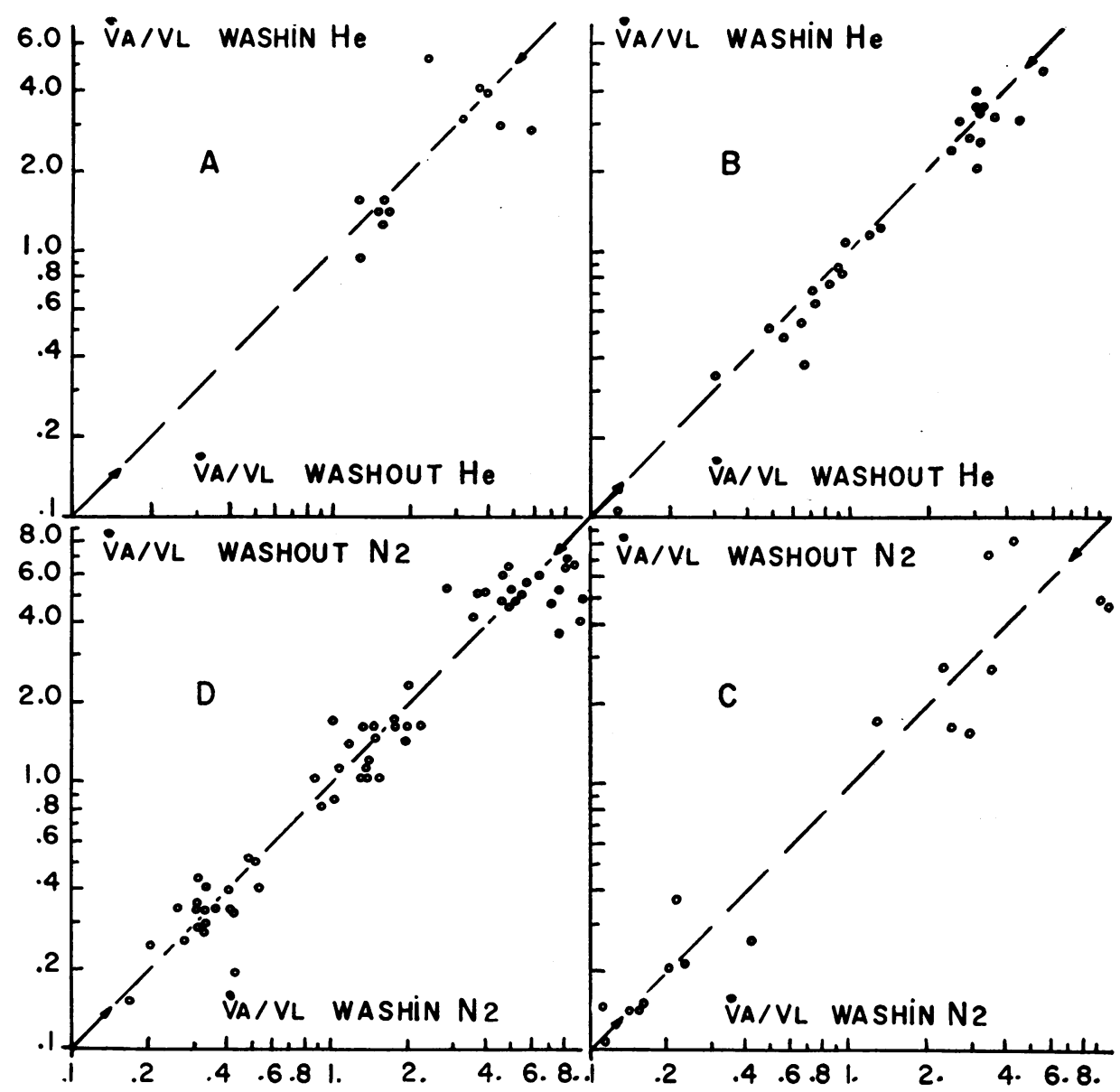

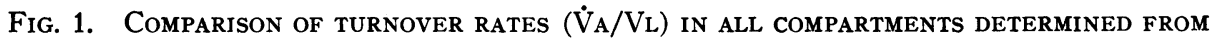
THE WASHOUT CURVE WITH THAT DETERMINED FROM THE WASHIN CURVE IN THE PRESENT AND IN OTHER studiEs. Quadrants A (normals) and B (patients) show the data of reference 8, quadrant $C$ corresponds to reference 1 , and quadrant $D$ represents the present series. The slopes of the regression lines are 1.03 in $\mathrm{A}, 0.99$ in $\mathrm{B}, 0.85$ in $\mathrm{C}$, and 0.93 in $\mathrm{D}$. There is no significant difference between those values and between each and the line of identity represented by the dashed line in each quadrant.

I, II, and III were, respectively, for $\mathrm{PCO}_{2}, 35.4$, 34.5 , and $41.8 \mathrm{~mm} \mathrm{Hg}$, and for $\mathrm{Po}_{2}, 103.1,104.9$, and $100.6 \mathrm{~mm} \mathrm{Hg}$. Although we recognize that the choice of the end tidal sample as representative of the alveolar gas is arbitrary, we feel that, in these patients, it may have been not greatly different from the mixed alveolar gas. Also, it must be remembered that, in our computation, the alveolar gas tensions are used only in determining the alveolar-arterial differences. Since the changes in perfusion among the three groups of subjects result from the changes in the $\mathrm{A}-\mathrm{aDCO}_{2}$ and $\mathrm{A}-\mathrm{aDN}_{2}$, the role of the alveolar values must be established in comparison to the role of the arterial values. It is evident from Table II that most of the changes in $\mathrm{A}-\mathrm{aD}$ from group I to group III come from the differences in the arterial blood gas tensions among the three groups, rather than from the variations in the end tidal values. Yet, insofar as the method used to select the alveolar gas tension is, to a certain extent, incorrect, it follows that $\mathrm{PACO}_{2}$ is overestimated, and $\mathrm{A}-\mathrm{aDCO}{ }_{2}$ is underestimated. This leads to a minimal $\dot{\mathrm{V}}_{\mathrm{A}} / \dot{Q}$ in the better ventilated compartment in relation to its volume. Similarly, $\mathrm{P}_{\mathrm{A}_{2}}$ is overestimated and $\mathrm{A}-\mathrm{aDN}_{2}$ is underestimated, resulting in a maximal value of $\dot{\mathrm{V}}_{\mathrm{A}} / \dot{\mathrm{Q}}$ in the third compartment. 
The assumption that the compartmental distribution of $\dot{\mathrm{V}}_{\mathrm{A}} / \dot{\mathrm{Q}}$ parallels the distribution of $\dot{\mathrm{V}}_{\mathrm{A}} / \mathrm{VL}$ is partly substantiated by the demonstration that, when the lung is analyzed into two compartments, the compartment with the lower turnover rate $\left(\dot{\mathrm{V}}_{\mathrm{A}} / \mathrm{VL}_{\mathrm{L}}\right)$ also has the lower $\dot{\mathrm{V}}_{\mathrm{A}} / \dot{\mathrm{Q}}$ $(1,2)$. The assumption here, then, is that $\dot{\mathrm{V}} \mathrm{A} / \dot{\mathrm{Q}}$ will continue to vary in the same direction as $\dot{\mathrm{VA}}_{\mathrm{A}} / \mathrm{VL}_{\mathrm{L}}$, when the lung is further subdivided into three compartments.

Actually, some of our data corroborate this hypothesis. If the units with the lowest $\dot{V}_{\mathrm{A}} / \mathrm{VL}_{\mathrm{L}}$ are also the units with lowest $\dot{\mathrm{V}}_{\mathrm{A}} / \dot{\mathrm{Q}}, \dot{\mathrm{V}}_{\mathrm{A}_{3}} / \mathrm{VL}_{\mathrm{L}_{3}}$ should be related to the arterial gas tension of $\mathrm{O}_{2}$, $\mathrm{N}_{2}$, or $\mathrm{CO}_{2}$, since the alveoli with a low $\dot{\mathrm{V}}_{\mathrm{A}} / \dot{\mathrm{Q}}$ contribute the most to the alteration of gas tensions of the mixed arterial blood. Figure 2 demonstrates such a relationship between $\mathrm{Pa}_{2}$ and $\dot{V}_{A_{3}} / \mathrm{VL}_{3}$, indicating that those lung units with the poorest ventilation in relation to volume must also have the lowest $\dot{V}_{A} / \dot{Q}$.

Thus, evidence seems to confirm the assumption that compartment 3 , being the same as the second compartment described in the work of others, has the lowest values for both $\dot{V}_{A} / V_{L}$ and $\dot{V}_{\mathrm{A}} / \dot{\mathrm{Q}}$.

Somewhat greater difficulty is encountered, however, in attempting to corroborate the hypothesis that, since $\dot{\mathrm{V}}_{\mathrm{A}_{1}} / \mathrm{VL}_{\mathrm{L}_{1}}>\dot{\mathrm{V}}_{\mathrm{A}_{2}} / \mathrm{VL}_{2}$, the relationship $\dot{\mathrm{V}}_{\mathrm{A}_{1}} / \dot{\mathrm{Q}}_{1}>\dot{\mathrm{V}}_{\mathrm{A}_{2}} / \dot{\mathrm{Q}}_{2}$ must also be true.

One might hope to demonstrate the existence of a relationship similar to that between the arterial gas tension and $\dot{\mathrm{V}}_{3} / \mathrm{VL}_{3}$ between the alveolar gas partial pressures and $\dot{V}_{A_{1}} / V_{L_{1}}$, if compartment 1 , which had the highest ventilation to lung volume ratio, also had the lowest $\dot{Q} / V_{L}$. It would seem, from the shape of a $\dot{\mathrm{V}}_{\mathrm{A}} / \dot{\mathrm{Q}}$ line plotted on the $\mathrm{O}_{2}-\mathrm{CO}_{2}$ diagram, that the $\mathrm{PACO}_{2}$ would be the alveolar gas partial pressure to consider. Plotting $\dot{\mathrm{V}}_{\mathrm{A}_{1}} / \mathrm{VL}_{1}$ against $\mathrm{PACO}_{2}$ failed to significantly demonstrate such a relationship, however, and a plot of $\mathrm{PACO}_{2}$ versus $\dot{\mathrm{V}}_{\mathrm{A}_{2}} / \mathrm{VL}_{2}$ was equally inconclusive. This failure does not negate the hypothesis, however, since the values of $\dot{V}_{A_{1}} / V_{L_{1}}$ in the three groups of sub-

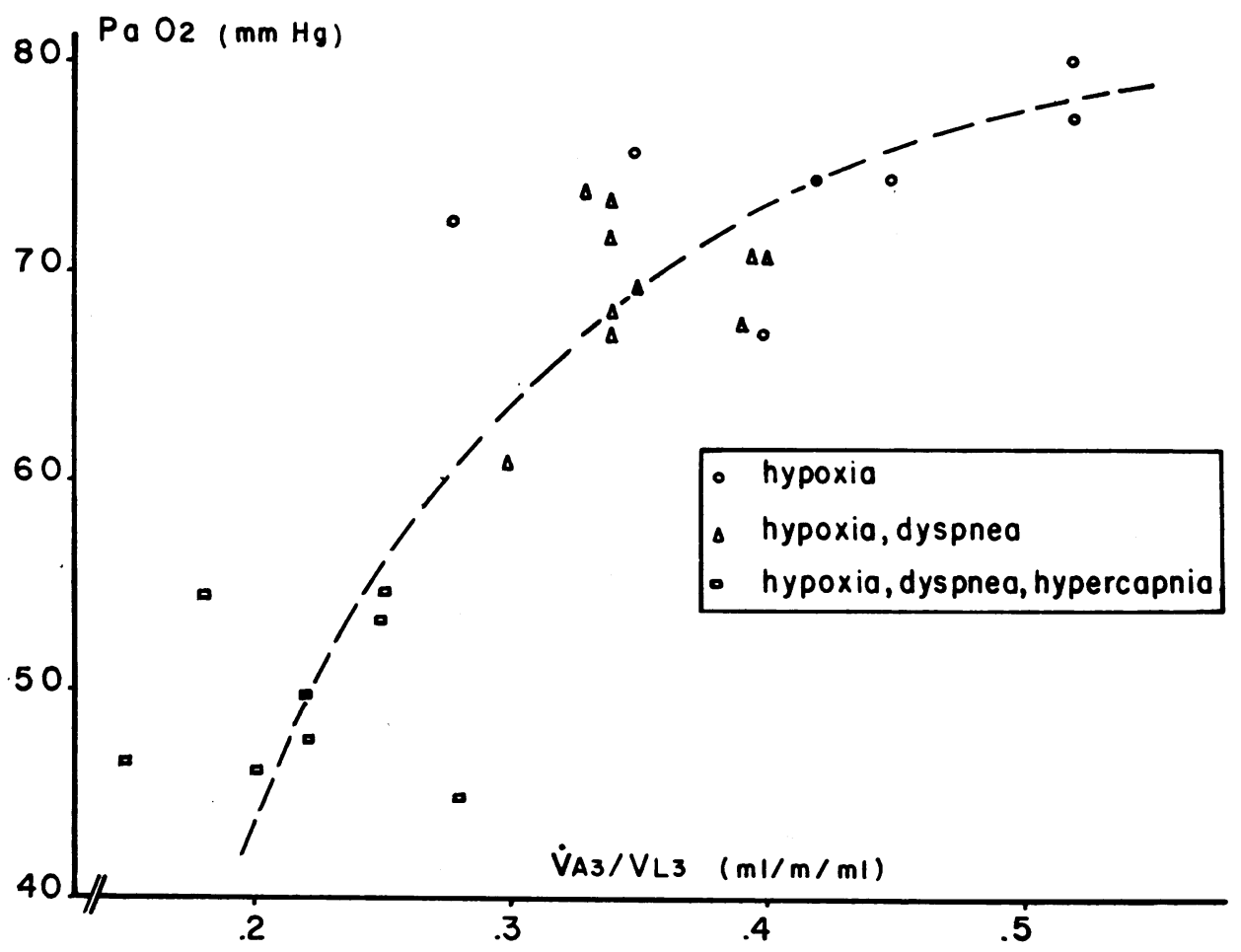

Fig. 2. Relationship Between OXYgen PRESSURE in the miXed ARterial blood ( $\mathrm{PaO}_{2}$ ) AND THE TURNOVER RATE OF COMPARTMENT $3\left(\dot{V}_{A_{3}} / V_{L_{3}}\right)$. The black symbols represent the mean of each group. The dashed line is the best fitted line. 
jects may have been too close together to permit graphic demonstration of such a relationship.

Probably the best support for the belief that the units with the highest $\dot{\mathrm{V}}_{\mathrm{A}} / \dot{\mathrm{Q}}$ units occur in compartment 1 is the following reasoning. The existence of abnormally high $\mathrm{A}-\mathrm{aDCO}_{2}$ makes it necessary to assume that, in these subjects, the scattering of $\mathrm{PCO}_{2}$ throughout the whole lung is greater than normal, and that, therefore, there are units in their lungs with $\dot{\mathrm{V}}_{\mathrm{A}} / \dot{\mathrm{Q}}$ that is higher than normal. The proportion of units with this high $\dot{V}_{\mathrm{A}} / \dot{Q}$ must be relatively quite small, however; otherwise, $\mathrm{CO}_{2}$ elimination would be more efficient than it is, because more blood would be flowing through better ventilated units. Thus, it seems most unlikely that the units with the highest $\dot{\mathrm{V}}_{\mathrm{A}} / \dot{\mathrm{Q}}$ occur in compartment 2 , which is larger than compartment 1.

Other investigators who studied the relationship between $\dot{V}_{A} / \dot{Q}$ and $\dot{V}_{A} / V_{L}$ in the anatomical divisions of the lung have found a high $\dot{V}_{\mathrm{A}} / \dot{Q}$ and a low $\dot{\mathrm{V}}_{\mathrm{A}} / \mathrm{V}_{\mathrm{L}}$ in the upper lobe and a low $\dot{\mathrm{V}}_{\mathrm{A}} / \dot{\mathrm{Q}}$ and a high $\dot{\mathrm{V}}_{\mathrm{A}} / \mathrm{VL}_{\mathrm{L}}$ in the lower lobe $(16$, 17). These results might appear to weaken our assumption regarding the parallel distribution of $\dot{\mathrm{V}}_{\mathrm{A}} / \dot{\mathrm{Q}}$ and $\dot{\mathrm{V}}_{\mathrm{A}} / \mathrm{V}_{\mathrm{L}}$ to the compartment, and also to contrast with the data we used to corroborate it $(1,2)$. The reasons for such a discrepancy lie in the differences in the approaches; a functionally defined compartment of any organ containing many units does not necessarily refer to an anatomical grouping of those units. With models it is possible to show that this paradoxical disagreement between the anatomically and functionally defined divisions of the lung depends upon the respective volume of each lobe, the absolute ventilation of each lobe, and the fact that the lobes are not uniform but contain both low and high $\dot{\mathrm{V}}_{\mathrm{A}} / \dot{\mathrm{Q}}$ units in different proportions. Thus the contradiction in these findings is actually only apparent, and the two concepts can be true at the same time.

The assumptions regarding the types of $\dot{\mathrm{V}}_{\mathrm{A}} / \dot{\mathrm{Q}}$ units causing $\mathrm{A}-\mathrm{aD}$ for $\mathrm{N}_{2}$ and $\mathrm{CO}_{2}$ have two implications that may be questioned. First it is implied that $\mathrm{PN}_{2}$ is the same in all units having a $\dot{V}_{A} / \dot{Q}$ higher than, or equal to, the mean $\dot{V}_{A} / \dot{Q}$, whereas $\mathrm{PCO}_{2}$ is identical in all alveoli having a $\dot{\mathrm{V}}_{\mathrm{A}} / \dot{Q}$ lower than, or equal to, the mean $\dot{\mathrm{V}}_{\mathrm{A}} / \dot{\mathrm{Q}}$. Only under such conditions could $\mathrm{A}-\mathrm{aDN}_{2}$ result entirely from the low $\dot{\mathrm{V}} \mathrm{A} / \dot{\mathrm{Q}}$ units, and $\mathrm{A}-\mathrm{aDCO}_{2}$ be caused exclusively by the high $\dot{V}_{A} / \dot{Q}$ units. As is evident from Rahn and Farhi's discussion (18), this is not exactly the case, although it can be shown that $\mathrm{A}-\mathrm{aDN} \mathrm{N}_{2}$ reflects primarily the presence of alveoli with low $\dot{\mathrm{V}} \mathrm{A} / \dot{Q}$ ratios, whereas $\mathrm{A}-\mathrm{aDCO}{ }_{2}$ describes alveoli with high $\dot{V}_{A} / \dot{Q}$ ratios. The second implication is that $\dot{\mathrm{V}}_{\mathrm{A}} / \dot{\mathrm{Q}}$ of the middle compartment $\left(\mathrm{VL}_{2}\right)$ is not different from the mean $\dot{V} A / Q$, and, therefore, does not contribute to arterioalveolar differences. This postulation, too, may not be entirely correct. The middle compartment is not absolutely uniform and, consequently, must contribute to some extent to the A-aD. Insofar as this postulate is incorrect, $\dot{Q}$ will be overestimated in $V_{L_{1}}$ and $V_{L_{3}}$, and underestimated in $V_{L_{2}}$. However, such an error tends to minimize, rather than exaggerate, the physiologically significant findings of this study.

Finally, it was assumed that the total blood flow for all subjects was identical and also that it was not affected by the severity of the disease. The choice of $5 \mathrm{~L}$ per minute is obviously arbitrary, but this is an admissable figure, since no subject had signs of circulatory or cardiac failure at the time of the experiment. Actually, in the method of computation used, differences in total blood flow would not greatly affect its distribution throughout the three lung compartments, nor would it markedly change the increase in dispersion of $\dot{Q}$ from group I to group III. On the other hand, the values of $\dot{Q} / V_{L}$ and $\dot{\mathrm{V}}_{\mathrm{A}} / \dot{\mathrm{Q}}$ would be affected, since they are calculated from the absolute values of $\dot{Q}$. If total blood flow were higher than $5 \mathrm{~L}$ per minute, $\dot{\mathrm{Q}} / \mathrm{VL}$ would be higher and $\dot{\mathrm{V}}_{\mathrm{A}} / \dot{\mathrm{Q}}$ would be lower than calculated. A lower than estimated blood flow would have the opposite effects. It is not clear from the literature whether there is any considerable change in blood flow in emphysematous patients before cardiac decompensation. Some published data $(19,20)$ indicate a decrease in cardiac output, another study (21) indicates no differences from normal, and a third group of data $(22,23)$ indicates a slight increase. In any event the selected condition, no change in $\dot{Q}$, has the effect of minimizing the variations in function within the lung. In addition, it can be readily shown that any variation of $\dot{Q}$ not 
TABLE $\mathrm{V}$

Comparison of present data for group III with values calculated in other studies

\begin{tabular}{|c|c|c|c|c|c|c|c|c|}
\hline Author and reference no. & $\begin{array}{l}\text { No. of lung } \\
\text { compart- } \\
\text { ments }\end{array}$ & $V_{L_{1}}$ & $\mathrm{VL}_{2}$ & $V_{L_{3}}$ & $\dot{\mathrm{V}}_{\mathrm{A}_{1} / \dot{\mathrm{Q}}_{1}}$ & $\dot{\mathrm{V}}_{\mathrm{A}_{2}} / \dot{\mathrm{Q}}_{2}$ & $\dot{\mathrm{V}}_{\mathrm{A}_{3}} / \dot{\mathrm{Q}}_{3}$ & $\begin{array}{c}\text { Range* } \\
\dot{\mathbf{V}}_{\mathbf{A}} / \dot{\mathbf{Q}}\end{array}$ \\
\hline $\begin{array}{l}\text { Briscoe and associates (1) } \\
\text { Finley }(2) \dagger \\
\text { Klocke and Farhi (24) } \\
\text { Briscoe and Cournand (13) } \ddagger\end{array}$ & $\begin{array}{l}2 \\
2 \\
2 \\
2\end{array}$ & $\begin{array}{c}\% \\
33.6 \\
32.0\end{array}$ & $\%$ & $\begin{array}{c}\% \\
66.4 \\
68.0\end{array}$ & $\begin{array}{l}2.24 \\
1.78\end{array}$ & & $\begin{array}{l}0.23 \\
0.30 \\
0.18 \\
0.25\end{array}$ & $\begin{array}{r}10.0 \\
6.5\end{array}$ \\
\hline $\begin{array}{l}\text { Group III, } \\
\text { present experiments }\end{array}$ & $\begin{array}{l}2 \\
3\end{array}$ & $\begin{array}{r}28.7 \\
8.3\end{array}$ & 20.4 & $\begin{array}{l}71.3 \\
71.3\end{array}$ & $\begin{array}{l}1.87 \\
1.71\end{array}$ & 0.78 & $\begin{array}{l}0.31 \\
0.31\end{array}$ & $\begin{array}{r}6.0 \\
22.0\end{array}$ \\
\hline
\end{tabular}

* Range in $\dot{\mathrm{V}} \mathrm{A} / \dot{\mathrm{Q}}$ is expressed by the difference between $\dot{\mathrm{V}}_{\mathrm{A}_{1}} / \mathrm{Q}_{1}$ and $\dot{\mathrm{V}}_{\mathrm{A}_{3}} / \dot{\mathrm{Q}}_{3}$.

$\dagger$ The results for $\dot{V}_{A} / \dot{Q}$ are relative values $\left(\% \dot{V_{A}} / \% \dot{Q}\right)$.

$\ddagger$ Results of the urinary nitrogen method.

exceeding $30 \%$ will not invalidate the final conclusions.

Table $\mathrm{V}$ lists the data available in the literature related to $\dot{\mathrm{V}} \mathrm{A} / \dot{Q}$ in a two compartment representation of the lung; these values are, wherever possible, correlated with the size of the compartment. The mean values for group III in the present study are included. This group alone was selected, because these subjects had a symptomatology that compared with that of the patients in the other reports. To make comparison easier, our results have been tabulated twice; they were analyzed into both two and three compartments. On the basis of the two compartment system, the range and absolute values of $\dot{\mathrm{V}}_{\mathrm{A}} / \dot{Q}$ in the various studies are remarkably similar. Our three compartment representation differs greatly, however, because of the discrepancy in the magnitude of the high $\dot{V}_{A} / \dot{Q}$ units. This difference demonstrates the importance of dividing the lung into as many compartments as possible in attempting to estimate accurately the functions of various parts of the lung. This increased subdivision becomes especially necessary if subjects with different clinical stages of emphysema are to be compared.

As shown in Table II, deepening hypoxia and hypercapnia develop as emphysema worsens. Such disturbances probably result from several different mechanisms.

Table IV shows that, with increasing severity of disease, there is a lowering of the over-all $\dot{\mathrm{V}}_{\mathrm{A}} / \dot{\mathrm{Q}}$ and a slight increase of the range of $\dot{\mathrm{V}}_{\mathrm{A}} / \dot{\mathrm{Q}}$. The change in over-all $\dot{V}_{A} / \dot{Q}$ is actually minimal and may be explained as a direct consequence of the hypoventilation resulting from progressive obstruction of the airways. A lowering in the over-all $\dot{\mathrm{V}}_{\mathrm{A}} / \dot{\mathrm{Q}}$ can explain hypoxia and eventually hypercarbia, but certainly not the existence of $\mathrm{A}-\mathrm{aD}$ if the $\dot{\mathrm{V}}_{\mathrm{A}} / \dot{\mathrm{Q}}$, regardless of its absolute value, is uniform throughout the lung. Therefore, an estimate of the alveolar and arterial concentrations of gas is important in the determination of the scattering of $\dot{V}_{A} / \dot{Q}$ in the lung. The range of $\dot{V}_{A} / \dot{Q}$ increased only between groups II and III; this change resulted from a decrease in $\dot{V}_{A} / \dot{Q}$ in compartment 3 and a tendency for $\dot{\mathrm{V}}_{\mathrm{A}} / \dot{\mathrm{Q}}$ in compartment 1 to increase in those patients with most advanced disease. As a result, the interval between the highest and the lowest $\dot{V}_{A} / \dot{Q}$ is twice as high in group III as in the first two groups of patients. Undoubtedly, these changes contribute in part to the production of hypoxia and hypercarbia and partly explain the alveolar-arterial differences in $\mathrm{O}_{2}, \mathrm{CO}_{2}$, and $\mathrm{N}_{2}$. There must be some further cause for the $\mathrm{A}-\mathrm{aD}$, however, since hypoxia deepened and the $\mathrm{A}-\mathrm{aD}$ increased between groups I and II without any demonstrable change in range of $\dot{V}_{A} / \dot{Q}$. Furthermore, it can be shown that the moderate increase in variance of $\dot{V}_{A} / \dot{Q}$ occurring in group III does not account entirely for the augmentation in the size of the A-aD. These modifications in the sizes of the different groups of lung units occurring during the course of the disease (Table III) would indicate that, with progression of the clinical disorder, there is an initial increase in the number of low $\dot{V}_{\mathrm{A}} / \dot{Q}$ units, which is followed by a further increase in size of the low $\dot{\mathrm{V}}_{\mathrm{A}} / \dot{Q}$ compartment and a simultaneous lowering of $\dot{\mathrm{V}}_{\mathrm{A}_{3}} / \dot{\mathrm{Q}}_{3}$. Some- 


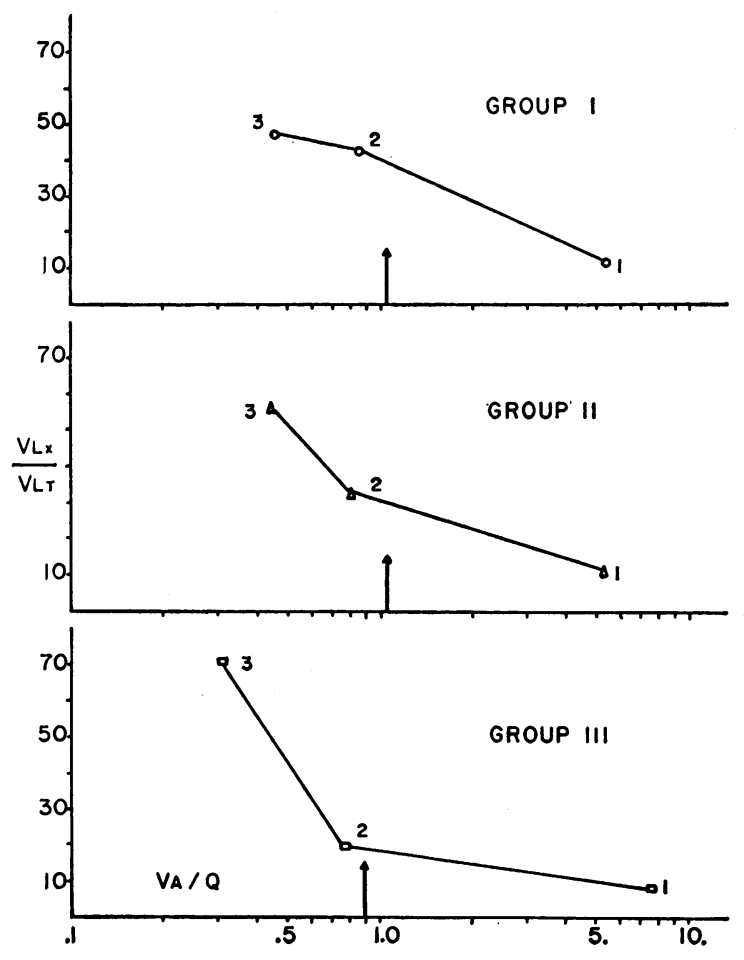

Fig. 3. Schematic Representation of the freQUENCY DISTRIBUTION CURVE IN THE THREE GROUPS OF SUBJECTS. 1, 2, and 3 refer to the three compartments, and $V_{L_{x}} / V_{L_{T}}$ indicates the fraction of lung volume of each compartment. The vertical arrow represents the over-all mean.

what comparable changes occurred in the group of high $\dot{V}_{A} / \dot{Q}$ units but were not as apparent, because this compartment is much smaller. Its absolute volume increased, however, between each patient group, even though its $\dot{\mathrm{V}}_{\mathrm{A}} / \dot{Q}$ increased only between groups II and III. Two changes in the frequency distribution curve of $\dot{V}_{\mathrm{A}} / \dot{Q}$ occurred, in addition to the increase in range. First, the shape of the curve was affected; the skewness increased, because more units were scattered away from the mean in both directions. As a result, the dispersion also increased (Figure 3).

Although the range of $\dot{\mathrm{V}} \mathrm{A} / \dot{\mathrm{Q}}$ is much larger in our experiments than it was in those done by Briscoe and associates (1), a relative compensating underperfusion of the poorly ventilated group of units appeared in our subjects as well as theirs. As pointed out by these authors, this factor is an important means of maintaining the $\dot{\mathrm{V}}_{\mathrm{A}} / \dot{\mathrm{Q}}$ dispersion within relatively narrow limits, thereby preventing further desaturation of arterial blood. This underperfusion occurs because the increase in size of compartment 3 as the disease progresses is relatively greater than the increase in blood flow to these poorly ventilated units. Obviously, greater perfusion of this compartment would result in a lower $\dot{\mathrm{V}}_{\mathrm{A}} / \dot{\mathrm{Q}}$, and, in turn, a lower $\mathrm{PO}_{2}$ and a higher $\mathrm{PCO}_{2}$ in the capillary blood leaving these units. This state would result in an increase in both hypoxia and the $\mathrm{A}-\mathrm{aDo}_{2}$. An overventilated, or high $\dot{\mathrm{V}}_{\mathrm{A}} / \dot{\mathrm{Q}}$, compartment need not be present to explain the A-aD for $\mathrm{O}_{2}$ and $\mathrm{N}_{2}$, since most of the variance in $\mathrm{PO}_{2}$ appears between the normally ventilated second and poorly ventilated third compartments. The addition of the first, or highly ventilated, compartment to the compartmental analysis causes only a moderate increase in the range of $\mathrm{PO}_{2}$ and $\mathrm{PN}_{2}$.

Consideration of the relationship between the different factors leading to hypoxia makes it apparent that the relative amount of perfusion to a poorly ventilated compartment is as important as its $\dot{V}_{A} / \dot{Q}$. This situation is somewhat analogous to the conditions associated with hypoxia resulting from a true anatomical shunt; the same level of unsaturation of the mixed arterial blood can be attained with a large shunt of moderately unsaturated blood as with a smaller shunt of more desaturated blood.

A similar mechanism is involved in hypercarbia and the $\mathrm{A}-\mathrm{aDCO}_{2}$. Figure 4 shows that, between groups II and III, the developing hypoventilation was associated with an increased $\mathrm{PCO}_{2}$ in alveolar gas, and, consequently, also in the mixed arterial blood, since the over-all $\dot{V}_{A} / \dot{Q}$ had decreased. However, the increased number of very low $\dot{\mathrm{V}}_{\mathrm{A}} / \dot{Q}$ units obviously resulted in an increase in the relative amount of blood from these units being added to the mixed arterial blood, thereby also contributing to the elevation of $\mathrm{PaCO}_{2}$. The importance of this factor is borne out by the significant increase in $\mathrm{Pa}_{\mathrm{CO}_{2}}$ between groups I and II, even though the subjects in these groups had the same ventilation. A difference between $\mathrm{PACO}_{2}$ and $\mathrm{Pa}_{\mathrm{CO}_{2}}$ can be present only if some alveolar units have a $\mathrm{PCO}_{2}$ that differs considerably from that of the rest of the lung; there is no other conceivable mechanism that would produce an $\mathrm{A}-\mathrm{aDCO}_{2}$. The actual $\mathrm{Pa}_{\mathrm{CO}_{2}}$ 


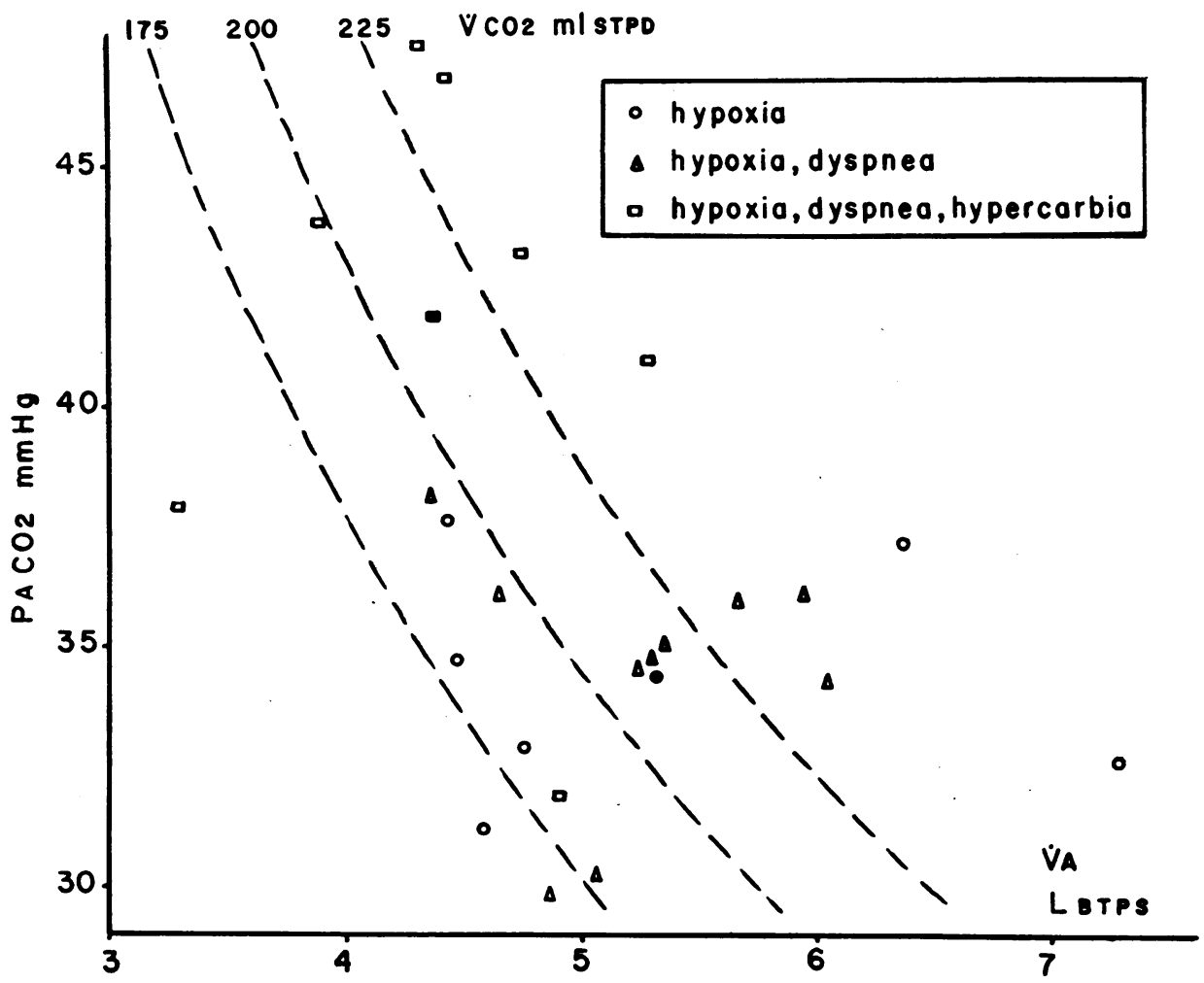

Fig. 4. Relationship between mixed alveolar $\mathrm{CO}_{2}$ PRESSURe (PACO 2 ) and total alVEOLAR VENTILATION $\left(\dot{V}_{A}\right)$. The dashed lines are isolines for various rates of $\mathrm{CO}_{2}$ elimination. They were calculated with the equation $\dot{\mathrm{V}} \mathrm{A}=\dot{\mathrm{V}} \mathrm{CO}_{2} \times 0.863 / \mathrm{PACO}_{2}$. $\dot{\mathrm{V}} \mathrm{CO}_{2}=$ volume of $\mathrm{CO}_{2}$ per unit time; STPD = standard temperature, pressure, dry; BTPS = body temperature, pressure, saturated with water. The black symbols represent the mean of each group.

is determined by the decrease in effective alveolar ventilation and by the rate of blood flow to the low $\dot{V}_{\mathrm{A}} / \dot{Q}$ group of units, but the $\mathrm{A}-\mathrm{aDCO}_{2}$ has to be produced by a group of high $\dot{\mathrm{V}}_{\mathrm{A}} / \dot{\mathrm{Q}}$ units that cause $\mathrm{PACO}_{2}$ not to increase as much as $\mathrm{Pa}_{\mathrm{CO}_{2}}$. If the $\dot{\mathrm{V}} \mathrm{A} / \dot{\mathrm{Q}}$ in these units had not been at the same high level in groups II and III, and if the number of those units had not been larger in group III, the $\mathrm{A}-\mathrm{aDCO}{ }_{2}$ could not have increased as greatly as it did, because there would have been a greater increase in $\mathrm{PACO}_{\mathrm{C}}$.

As shown previously (25), the two factors related to the value of the difference between $\mathrm{A}-\mathrm{aDO}_{2}$ and the sum of $\mathrm{A}-\mathrm{aDCO}_{2}+\mathrm{A}-\mathrm{aDN}_{2}$ are the true anatomical shunt, and the effect of the $\mathrm{O}_{2}$ dissociation curve. While subjects breathe room air, the effect of the shunt component on this value is small; the effect of the dissociation curve is more important. The reverse is true for high $\mathrm{F}_{\mathrm{I}_{2}}$. The absence of any very sig- nificant difference in the values of $\mathrm{A}-\mathrm{aDO}_{2}-$ $\left(\mathrm{A}-\mathrm{aDCO} \mathrm{CO}_{2}+\mathrm{A}-\mathrm{aDN}_{2}\right)$ among subjects of all three groups suggests that the size of the anatomical shunt was probably the same in all. There probably was no important increase in the range of $\dot{V}_{A} / \dot{Q}$, since a change would have occurred only if the effect of the $\mathrm{O}_{2}$ dissociation curve had increased.

The increase in $\mathrm{A}-\mathrm{aDO}_{2}$ and $\mathrm{A}-\mathrm{aDN}_{2}$ upon changing from air to $\mathrm{O}_{2}$ breathing was not unexpected, since it was due primarily to the low $\dot{V}_{A} / \dot{Q}$ group of units (5). As a true steady state obviously was not reached in so short a time, the values obtained for these $\mathrm{A}-\mathrm{aD}$, which did not remain constant, could not be considered as final ones for the particular high $\mathrm{FI}_{\mathrm{O}_{2}}$ used (12).

There is no general agreement on the mechanism for the increase in $\mathrm{A}-\mathrm{aDCO}_{2}$ consistently observed to follow a change from breathing air to breathing a gas providing a high $\mathrm{FI}_{\mathrm{O}_{2}}$. Some 


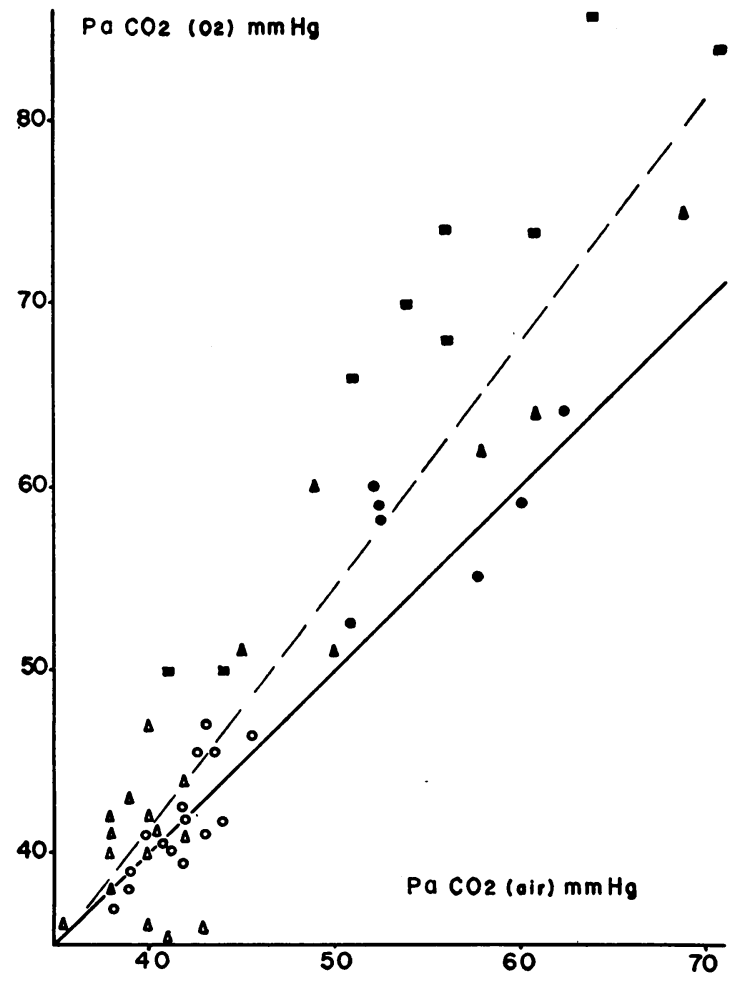

Fig. 5. Comparison of $\mathrm{CO}_{2}$ PRESSURE in MiXed ARTERIAL BLOOD $\left(\mathrm{PaCO}_{2}\right)$ DURING ROOM AIR BREATHING WITH THAT DURING THE HIGH $\mathrm{O}_{2}$ BREATHING PERIOD IN THE PRESENT AND IN OTHER STUDIES. The open symbols correspond to $\mathrm{PaCO}_{2}$ lower than $45 \mathrm{~mm} \mathrm{Hg}$, and the black, $\mathrm{PaCO}_{2}$ higher than $45 \mathrm{~mm} \mathrm{Hg}$ during air breathing ( $\Delta$ from reference $29, \square$ from reference 1 , $\bullet$ from present series, group III, $\Delta$ from reference 29 , and $O$ from present series, groups I and II). The plain line with a $45^{\circ}$ angle represents the line of identity; the dashed line is the calculated regression line. The difference between those two lines demonstrates that the increase of $\mathrm{PaCO}_{2}$ with $\mathrm{O}_{2}$ breathing is related to the original $\mathrm{PaCO}_{2}$.

authors have suggested that this increase is derived mainly from a change in $\dot{V}_{A} / \dot{Q}(26)$, or from the number of high $\dot{\mathrm{V}}_{\mathrm{A}} / \dot{\mathrm{Q}}$ units (14), whereas others have postulated that it is a result of the Haldane effect of the $\mathrm{CO}_{2}$ dissociation curve (27). Comparison of the $\mathrm{Pa}_{\mathrm{CO}_{2}}$ and $\mathrm{PACO}_{2}$ before and after changing from low to high $\mathrm{FI}_{\mathrm{O}_{2}}$ indicates the source of the change of $\mathrm{A}-\mathrm{aDCO}_{2}$ (28). In normal subjects and those with only minimal disease, only a decrease in the $\mathrm{PA}_{\mathrm{CO}_{2}}$ occurs $(14,26)$. In patients with advanced emphysema and hypercarbia, however, this same directional change in the $\mathrm{PACO}_{2}$ is accompanied by an increase in $\mathrm{PaCO}_{2}$ that is of much greater significance (Figure 5). This difference might be explained by a Haldane effect occurring when these patients' blood (the largest portion of which remains unsaturated while the patient breathes room air) becomes saturated at the higher $\mathrm{FI}_{\mathrm{O}_{2}}$.

\section{Summary}

The physiologic changes associated with the progression of disease in chronic pulmonary emphysema were examined in a comparative study of the several factors related to respiratory gas exchange in 22 patients at different stages of this disorder. Factors considered included alveolar ventilation, lung volume, blood flow, and the relationships of these to each other in a three compartment system; the alveolar-arterial differences of each of the three respiratory gases, $\mathrm{O}_{2}, \mathrm{CO}_{2}$, and $\mathrm{N}_{2}$; and the distribution of the ventilation to perfusion ratios $\left(\dot{\mathrm{V}}_{\mathrm{A}} / \dot{\mathrm{Q}}\right)$ throughout the lung.

Our findings confirm the fact that changes in the distribution of ventilation to perfusion ratios appear to be the factors mainly responsible for progressive impairment of gas exchange in patients with emphysema graded according to ventilatory impairment. Although there is a lowering of the over-all $\dot{\mathrm{V}}_{\mathrm{A}} / \dot{\mathrm{Q}}$ that accompanies worsening of the clinical signs, this is actually probably not as significant in the production of hypoxia and hypercarbia as the changes in distribution of units throughout the lung. These changes include increases in the range of $\dot{V}_{A} / \dot{Q}$, skewness of the frequency distribution curve, and dispersion. In other words, as the clinical disease advances, there appears to be a decrease in the number of alveolar units with a normal ventilation to blood flow ratio as more and more units move away from this category in both directions; most become low units, while some others are becoming high $\dot{\mathrm{V}} / \mathrm{Q} \dot{Q}$ units at the same time.

The rate of blood flow, or percentage of total blood flow, going to alveolar units with a low $\dot{\mathrm{V}}_{\mathrm{A}} / \dot{\mathrm{Q}}$ is equally as important to the production of hypoxia and $\mathrm{CO}_{2}$ retention as the actual level of low $\dot{\mathrm{V}} \mathrm{A} / \dot{\mathrm{Q}}$ ratio value.

\section{Acknowledgments}

The authors express their appreciation to Dr. C. J. Martin for helpful comments and suggestions. They are indebted to Dr. W. Briscoe for his aid and constructive 
criticism in the revision of this manuscript. They also acknowledge the proficient technical assistance of $\mathrm{C}$. Aucutt and thank Instrumentation Associates, Inc., for the generous loan of the Godart pneumotachograph.

\section{References}

1. Briscoe, W. A., E. M. Cree, J. Filler, H. E. J. Houssay, and A. Cournand. Lung volume, alveolar ventilation and perfusion interrelationships in chronic pulmonary emphysema. J. appl. Physiol. 1960, 15, 785.

2. Finley, T. N. The determination of uneven pulmonary blood flow from the arterial oxygen tension during nitrogen washout. J. clin. Invest. 1961, 40, 1727.

3. Baldwin, E. deF., A. Cournand, and D. W. Richards. Pulmonary insufficiency: III A study of 122 cases of chronic pulmonary emphysema. Medicine (Baltimore) 1949, 28, 201.

4. Raine, J. M., and J. M. Bishop. A-a difference in $\mathrm{O}_{2}$ tension and physiological dead space in normal man. J. appl. Physiol. 1963, 18, 284.

5. Lenfant, C. Measurement of ventilation/perfusion distribution with alveolar-arterial differences. J. appl. Physiol. 1963, 18, 1090.

6. Baldwin, E. deF., A. Cournand, and D. W. Richards. Pulmonary insufficiency: I. Physiological classification, clinical methods of analysis, standard values in normal subjects. Medicine (Baltimore) 1948, 27, 243.

7. Lenfant, C., and C. Aucutt. Oxygen uptake and change in carbon dioxide tension in human blood stored at $37^{\circ}$ C. J. appl. Physiol. 1965, 20, 503.

8. Robertson, J. S., W. E. Siri, and H. B. Jones. Lung ventilation patterns determined by analysis of nitrogen elimination rates; use of the mass spectrometer as a continuous gas analyzer. J. clin. Invest. $1950,29,577$.

9. Briscoe, W. A., and A. Cournand. Uneven ventilation of normal and diseased lungs studied by an open-circuit method. J. appl. Physiol. 1959, 14, 284.

10. Ball, W. C., Jr., P. B. Stewart, L. G. S. Newsham, and D. V. Bates. Regional pulmonary function studied with xenon ${ }^{133}$. J. clin. Invest. 1962, 41, 519.

11. West, J. B., and C. T. Dollery. Distribution of blood flow and ventilation-perfusion ratio in the lung, measured with radioactive $\mathrm{CO}_{2}$. J. appl. Physiol. 1960, 15, 405.

12. Torres, G. E., C. T. Huang, and H. A. Lyons. Increase in venous admixture during breathing $100 \%$ oxygen. Physiologist 1963, 6, 287.

13. Briscoe, W. A., and A. Cournand. The degree of variation of blood perfusion and of ventilation within the emphysematous lung, and some related considerations in Ciba Foundation Symposium on Pulmonary Structure and Function, A. V. S. de Reuck and M. O'Connor, Eds. Boston, Little, Brown, 1962, p. 304.
14. Lenfant, C. Effect of high $\mathrm{F}_{\mathrm{I}_{2}}$ on measurement of ventilation/perfusion distribution in man at sea level. Ann. N. Y. Acad. Sci. 1965, 121, 797.

15. Marshall, R., D. V. Bates, and R. V. Christie. Fractional analysis of the alveolar air in emphysema. Clin. Sci. 1952, 11, 297.

16. Martin, C. J., and A. C. Young. Lobar ventilation in man. Amer. Rev. Tuberc. 1956, 73, 330.

17. Young, A. C., C. J. Martin, and W. R. Pace, Jr. Effect of expiratory flow patterns on lung emptying. J. appl. Physiol. 1963, 18, 47.

18. Rahn, H., and L. E. Farhi. Ventilation-perfusion relationship in Ciba Foundation Symposium on Pulmonary Structure and Function, A. V. S. de Reuck and M. O'Connor, Eds. Boston, Little, Brown, 1962, p. 139.

19. Blount, S. G. Cardiac output in pulmonary emphysema in Pulmonary Circulation, W. Adams and I. Veith, Eds. New York, Grune \& Stratton, 1959, p. 160.

20. Williams, J. F., and R. H. Beknke. The effect of pulmonary emphysema upon cardiopulmonary hemodynamics at rest and during exercise. Ann. intern. Med. 1964, 60, 824.

21. Kitchin, A. H., C. P. Lowther, and M. B. Matthews. The effects of exercise and of breathing oxygenenriched air on the pulmonary circulation in emphysema. Clin. Sci. 1961, 21, 93.

22. Ferrer, M. I., and R. M. Harvey. Decompensated pulmonary heart disease with a note on the effect of digitalis in Pulmonary Circulation, W. Adams and I. Veith, Eds. New York, Grune \& Stratton, 1959, p. 171.

23. Woolf, C. R., R .W. Gunton, and W. Paul. Cardiac output and blood volume in chronic cor pulmonale. Canad. med. Ass. J. 1961, 85, 1271.

24. Klocke, R. A., and L. E. Farhi. Simple method for determination of perfusion and ventilation-perfusion ratio of the underventilated elements (the slow compartment) of the lung. Technical documentary report no. AMRL-TDR-63-103 (1), 1963, 140.

25. Lenfant, C. Measurement of factors impairing gas exchange in man with hyperbaric pressure. J. appl. Physiol. 1964, 19, 189.

26. Larson, C. P., Jr., and J. W. Severinghaus. Postural variations in dead space and $\mathrm{CO}_{2}$ gradients breathing air and $\mathrm{O}_{2}$. J. appl. Physiol. 1962, 17, 417.

27. Bryan, A. C., L. G. Bentivoglio, F. Beerel, H. MacLeish, A. Zidulka, and D. V. Bates. Factors affecting regional distribution of ventilation and perfusion in the lung. J. appl. Physiol. 1964, 19, 395.

28. Lenfant, C. Arterial-alveolar difference in $\mathrm{PCO}_{2}$ during air and $\mathrm{O}_{2}$ breathing. In preparation.

29. Said, S. I., and C. M. Banerjee. Venous admixture to the pulmonary circulation in human subjects breathing 100 per cent oxygen. J. clin. Invest. 1963, 42, 507. 